\title{
Ultrafine Aerosol Particle Sizer Based on Piezoresistive Microcantilever Resonators with Integrated Air-Flow Channel
}

\author{
Maik Bertke $^{1}\left(\mathbb{D}\right.$, Ina Kirsch ${ }^{2}$, Erik Uhde ${ }^{2}(D)$ and Erwin Peiner ${ }^{1, *(D)}$ \\ 1 Institute for Semiconductor Technology and Laboratory for Emerging Nanometrology (LENA), \\ Technische Universität Braunschweig, Hans-Sommer-Str. 66/Langer Kamp 6a, \\ 38106 Braunschweig, Germany; m.bertke@tu-bs.de \\ 2 Fraunhofer Wilhelm-Klauditz-Institut (WKI), Bienroder Weg 54E, 38106 Braunschweig, Germany; \\ ina.kirsch@wki.fraunhofer.de (I.K.); erik.uhde@wki.fraunhofer.de (E.U.) \\ * Correspondence: e.peiner@tu-bs.de; Tel.: +49-531-391-65332
}

check for updates

Citation: Bertke, M.; Kirsch, I.; Uhde, E.; Peiner, E. Ultrafine Aerosol Particle Sizer Based on Piezoresistive Microcantilever Resonators with Integrated Air-Flow Channel. Sensors 2021, 21, 3731. https://doi.org/ $10.3390 / \mathrm{s} 21113731$

Academic Editor: George Amarandei

Received: 12 May 2021

Accepted: 24 May 2021

Published: 27 May 2021

Publisher's Note: MDPI stays neutral with regard to jurisdictional claims in published maps and institutional affiliations.

Copyright: (c) 2021 by the authors. Licensee MDPI, Basel, Switzerland. This article is an open access article distributed under the terms and conditions of the Creative Commons Attribution (CC BY) license (https:// creativecommons.org/licenses/by/ $4.0 /)$.

\begin{abstract}
To monitor airborne nano-sized particles (NPs), a single-chip differential mobility particle sizer (DMPS) based on resonant micro cantilevers in defined micro-fluidic channels $(\mu \mathrm{FCs})$ is introduced. A size bin of the positive-charged fraction of particles herein is separated from the air stream by aligning their trajectories onto the cantilever under the action of a perpendicular electrostatic field of variable strength. We use previously described $\mu \mathrm{FCs}$ and piezoresistive micro cantilevers (PMCs) of $16 \mathrm{ng}$ mass fabricated using micro electro mechanical system (MEMS) technology, which offer a limit of detection of captured particle mass of $0.26 \mathrm{pg}$ and a minimum detectable particulate mass concentration in air of $0.75 \mu \mathrm{g} / \mathrm{m}^{3}$. Mobility sizing in 4 bins of a nebulized carbon aerosol NPs is demonstrated based on finite element modelling (FEM) combined with a-priori knowledge of particle charge state. Good agreement of better than $14 \%$ of mass concentration is observed in a chamber test for the novel MEMS-DMPS vs. a simultaneously operated standard fast mobility particle sizer (FMPS) as reference instrument. Refreshing of polluted cantilevers is feasible without de-mounting the sensor chip from its package by multiply purging them alternately in acetone steam and clean air.
\end{abstract}

Keywords: differential mobility particle sizer; micro electro mechanical system; micro-fluidic channel; piezoresistive micro cantilever; picogram balance; ultrafine particles; carbon aerosol

\section{Introduction}

Air quality is a most important factor of a healthy life with high current relevance. For example, long-term exposure to a polluted ambient can be a similar hazard to life expectancy as inhaling tobacco smoke and about $15 \%$ of the worldwide deaths from the current coronavirus disease 2019 (COVID-19) pandemic might be related to a longlasting exposure to air polluted by anthropogenic sources (e.g., particulate matter (PM) from combustion sources) [1,2]. Air-polluting PM is categorized according to its size, i.e., the commonly monitored $\mathrm{PM}_{10}, \mathrm{PM}_{2.5}$ and $\mathrm{PM}_{1}$ fractions denoting $\mathrm{PM}$ of aerodynamic diameter less than $10 \mu \mathrm{m}, 2.5 \mu \mathrm{m}$ and $1 \mu \mathrm{m}$, respectively. Moreover, ultrafine particles (UFPs) or $\mathrm{PM}_{0.1}$ of a diameter of less than $100 \mathrm{~nm}$ have been recognized, which are in large amounts generated by traffic, e.g., through combustion by diesel (20 to $130 \mathrm{~nm}$ ) and gasoline engines (40 to $80 \mathrm{~nm}$ ) [3]. In air, $\mathrm{PM}_{0.1}$ is more persistent than larger particulates and can penetrate lungs deeper with the ability to translocate into the circulatory system. Oxidative stress associated with exposure to UFPs comprising hazardous components can cause inflammatory processes, which can lead to significant consequences to the respiratory conditions as well as genotoxic, mutagenic, and carcinogenic activity in human beings depending on the additives' toxicity [3]. For example, cerium dioxide and titanium dioxide instilled on lung epithelial cells and macrophages can either trigger moderate effects or initiate cytotoxicity, pro-inflammatory gene expression and genotoxicity [4]. On blood cell 
surfaces UFPs may activate angiotensin-converting enzyme 2 (ACE-2) receptors, which are known to be involved in the infection process of cells by COVID-19 [2].

A most practicable way to protect people from excessive exposure to UFP pollution is to provide them with lightweight and battery-powered personal monitors. For indoor personal exposure monitoring, low-cost optical particle counters based on light scattering are commercially available, which, however, cannot accurately measure particles smaller than $0.3 \mu \mathrm{m}[3,5,6]$. A minimum particle size of $140 \mathrm{~nm}$ was reported for a Fresnel ring lens-based optical particle counter, while counters based on complementary metal-oxidesemiconductor (CMOS) image sensing or holographic detection combined with extensive image processing are limited to the particle size range above $3 \mu \mathrm{m}$ [7].

Gravimetric methods using resonant sensors, e.g., based on micro or nano electro mechanical systems (M/NEMS) can provide a sufficiently high sensitivity to detect nanosized particles (NPs) [8]. For example, $\mathrm{TiO}_{2} \mathrm{NPs}$ were sampled on an array of tiny $\mathrm{Si}$ nanowire resonators and detected by a down-shift of resonance frequency in a scanning electron microscope [9]. The reported mass resolution of $31.6 \mathrm{fg}$ corresponds to limit of detection (LOD) of 5 to 6 NPs of a mean diameter of $125 \mathrm{~nm}$. A direct mass-reading device was demonstrated by a weakly coupled piezoelectric MEMS-resonator sensor showing an LOD of $2.6 \mathrm{pg}$ with $100 \mathrm{~nm}$ soot particles [10]. Unfortunately, particle size distributions have not been measured so far using such M/NEMS resonant sensors, which would nevertheless be necessary for a more comprehensive evaluation of air quality.

Owing to their sensitive dynamic response, micro cantilevers have attracted considerable interest for high-resolution mass sensing [11]. Correspondingly, we report in this study on a piezoresistive micro cantilever (PMC) for NP size distribution measurement, which is integrated in a micro-fluidic channel $(\mu \mathrm{FC})$. Based on mobility separation of charged particles flowing in the $\mu \mathrm{FC}$, we describe a procedure for analyzing the size distribution of polydisperse aerosols at different sampling voltages, i.e., the MEMS device is operated as a differential mobility particle sizer (MEMS-DMPS). For validating this concept we use carbon engineered NPs, which can be considered as a model aerosol for environmental $\mathrm{PM}_{0.1}$, whose mass is largely composed of carbonaceous material (elemental, organic or black carbon).

In the following paper, we first briefly review and evaluate in Section 2 a selection of recently reported portable gravimetric airborne particle sensors [12-25]. In Section 3, we describe design, fabrication and test of a recently proposed highly sensitive MEMS-based $\mathrm{NP}$ sensor containing a $\mu \mathrm{FC}$ with an integrated PMC $[26,27]$. As the essential outcome of the present work, a novel procedure is then described in Section 4 for retrieving particlesize distributions of a carbon NP aerosol from the sensor output. Finally, regeneration of a NP-loaded cantilever is addressed in Section 5.

\section{Portable Gravimetric Aerosol Monitors with Particle-Size Separation}

Size-selective gravimetric PM sensing is based on particle sampling on a resonant device using aerodynamic (filter, impactor), electrostatic (mobility analyzer), or thermophoretic techniques. Numerous sampling-and-separation techniques have been reported for direct-reading/real-time PM monitoring based on micro filter $(\mu \mathrm{F})$, impactor filter (IF), virtual impactor (VI), cascade impactor (CI), differential mobility analyzer (DMA), etc. [12]. A selection of recently published wearable devices and their characteristics is presented in Table 1. Such gravimetric sensors can monitor $\mathrm{PM}_{1}$ and $\mathrm{PM}_{2.5}$ of concentrations as low as $0.7 \mu \mathrm{g} / \mathrm{m}^{3}$ to $50 \mu \mathrm{g} / \mathrm{m}^{3}$ and are based on MEMS electrothermal-piezoresistive cantilever (MEMS-EPC), thermal-piezoresistive resonator/oscillator MEMS-TPR/O, on micro quartz tuning fork (MQTF), surface acoustic wave resonator (SAW), or film bulk acoustic resonator (FBAR) devices. Particle-size separation is realized by filters and/or impactors, which remove particles from the air flow above a certain size limit set by the particle range to be captured on the resonator. 
Table 1. Gravimetric aerosol particle detectors for personal air-quality monitoring. For comparison, three electrometer-based (EM) setups are included offering the capability of particle separation into several size bins. Abbreviations are given below ${ }^{1}$.

\begin{tabular}{|c|c|c|c|c|c|c|}
\hline Detection Method & $\begin{array}{c}\text { LOD } \\
\left(\mu \mathrm{g} / \mathrm{m}^{3}\right)\end{array}$ & Sampling Method & Separating Method & No of Bins & Particle Size & Ref. \\
\hline \multirow{3}{*}{ MEMS-EPC } & 15 & \multirow{2}{*}{$\mathrm{EP}$} & $\mu \mathrm{F} / \mathrm{IF}$ & - & $\mathrm{PM}_{2.5} / \mathrm{PM}_{1}$ & [13] \\
\hline & $1.4 / 0.7$ & & - & - & NPs & [14] \\
\hline & 2 & \multirow[t]{2}{*}{$\mu \mathrm{F}$} & $\mu \mathrm{F}$ & - & $\mathrm{PM}_{2.5}$ & [15] \\
\hline MEMS-TPO & 50 & & - & - & $\mathrm{PM}_{2.5}$ & [16] \\
\hline MQTF & 2 & \multirow[t]{2}{*}{ I } & IF & - & $\mathrm{PM}_{2.5}$ & [17] \\
\hline SAW & - & & \multirow{2}{*}{ VI } & - & $\mathrm{PM}_{1}$ & [18] \\
\hline FBAR & - & $\mathrm{TP}$ & & - & $\mathrm{PM}_{2.5}$ & [19] \\
\hline MEMS-TPoS & 10 & \multirow{2}{*}{ I } & \multirow{2}{*}{ 2-stage CI } & 1 & 1.03 to $2.54 \mu \mathrm{m}$ & [20] \\
\hline MEMS-TPR & - & & & 1 & 40 to $140 \mathrm{~nm}$ & [21] \\
\hline \multirow{3}{*}{ EM } & - & $\mathrm{EP}$ & \multirow{2}{*}{ DMA } & 7 & 50 to $200 \mathrm{~nm}$ & [22] \\
\hline & - & $\mathrm{DF}$ & & 20 & 50 to $200 \mathrm{~nm}$ & [23] \\
\hline & - & $\mathrm{EP}$ and $\mathrm{I}$ and $\mu \mathrm{F}$ & DMA and IF & continuous & 20 to $400 \mathrm{~nm}$ & [24] \\
\hline
\end{tabular}

${ }^{1}$ Limit of detection (LOD), particulate matter of aerodynamic diameter of less than $2.5 \mu \mathrm{m}$ and $1 \mu \mathrm{m}$, respectively $\left(\mathrm{PM}_{2.5}\right.$ and $\left.\mathrm{PM}_{1}\right)$, micro electro mechanical system (MEMS), electrothermal-piezoresistive cantilever (EPC), thermal-piezoresistive oscillator/resonator (TPO/R), micro quartz tuning fork (MQTF), surface acoustic wave (SAW), film bulk acoustic resonator (FBAR), thin-film piezoelectric-on-silicon $(\mathrm{TPoS})$ oscillator, electrometer (EM), electrophoresis (EP), thermophoresis (TP), micro filter ( $\mu \mathrm{F})$, Impact (I), disc filter (DF), impactor filter (IF), virtual impactor (VI), cascade impactor (CI), differential mobility analyzer (DMA).

The portable $(0.4 \mathrm{~kg})$ and battery-powered $(1.25 \mathrm{~W})$ particle monitor Cantor (Figure 1$)$ has a micro filter $(\mu \mathrm{F})$ or an impactor filter (IF) at its inlet for separating coarse particles of $2.5 \mu \mathrm{m}$ and $1 \mu \mathrm{m}$, respectively, from a sucked-in air flow and was shown to sample carbon, titanium, silica and silver NPs on an electrothermal-piezoresistive cantilever (MEMSEPC) $[13,25]$. Recently, its limit of detection of LOD $=3 \times \delta f / S=15 \mu \mathrm{g} / \mathrm{m}^{3}$ (with the minimum detectable frequency shift rate $\delta f / \delta t$ and the mass-concentration sensitivity $S$ ) could be improved to $1.4 \mu \mathrm{g} / \mathrm{m}^{3}$ by reducing a parasitic feedthrough between the thermal actuator and the piezoresistive Wheatstone bridge [13]. In this report, furthermore, using a tiny commercial piezoresistive atomic-force-microscopy cantilever (mass of $\sim 31 \mu$ g, i.e., by a factor 20 lower than the Cantor cantilever) with thermal bimorph actuator, the LOD was further reduced to $0.7 \mu \mathrm{g} / \mathrm{m}^{3}$.

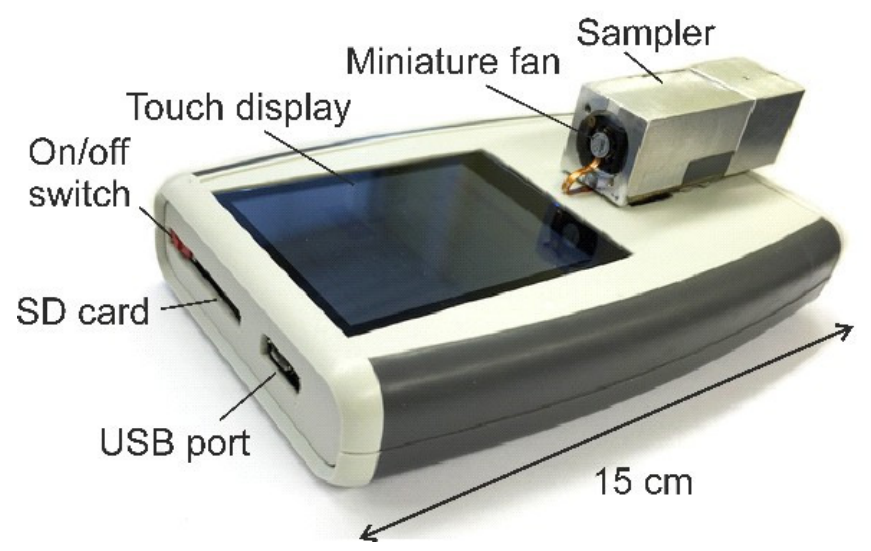

Figure 1. Pocket-size, battery-powered NP monitor "Cantor" with a weight of $0.4 \mathrm{~kg}$ and a power consumption of $1.25 \mathrm{~W}$.

For micro-particle separation and detection, a $\mu \mathrm{FC}$ with micro filter $(\mu \mathrm{F})$ was proposed for collecting particles larger than the filter spacing of $1.1 \mu \mathrm{m}$ [15]. The $\mu \mathrm{FC}$ was integrated in a MEMS-EPC for resonant gravimetric detection. Alternatively, a gated CMOS thermalpiezoresistive oscillator (MEMS-TPO) with an impactor for $\mathrm{PM}_{2.5}$ was reported for cigarette smoke detection [16].

A micro quartz tuning fork (MQTF) with impact sampling was reported to yield an LOD of $2 \mu \mathrm{g} / \mathrm{m}^{3}$ with $\mathrm{PM}_{2.5}$ [17]. Using a 3-D printed virtual impactor (VI) particles smaller 
than $1.05 \mu \mathrm{m}$ are separated into a major flow channel and impacted onto a surface acoustic wave (SAW) detector, where a layer of glycerol film served to enhance surface adhesion for capturing them [18]. This way, the $\mathrm{PM}_{1}$ fraction of silicon dioxide particles with diameters in the range of 0.1-4 $\mu \mathrm{m}$ was measured. In another approach, a VI was combined with an FBAR for $\mathrm{PM}_{2.5}$ detection [19]. In this case instead of impact, thermophoresis (TP) was used for sampling monodisperse polystyrene latex beads. Nevertheless, in these approaches a further separation of the sampled particle fraction into size bins was lacking.

For separating particles of a defined size bin from a polydisperse aerosol, a cascaded arrangement of two impactors (CI) connected in series in the air flow was proposed for $\mathrm{PM}_{2.5}$ [20] and $\mathrm{PM}_{0.1}$ [21]. For detection, either a thin-film piezoelectric-on-silicon (TPoS) oscillator or a thermal-piezoresistive lateral resonator (TPR) was used, offering fixed bin sizes of 1.03 to $2.54 \mu \mathrm{m}$ and 40 to $140 \mathrm{~nm}$, respectively.

Sizing using an impactor or a filter, by which particles of a specific size are separated from the total flow according to their aerodynamic and geometric diameters, respectively, suffers from certain drawbacks. The impactor-based approaches require noisy and powerconsumptive pumps for achieving sufficiently high particle velocities and flow rates. Furthermore, to reduce re-bouncing of particles from the mass-detecting resonator body, it should be coated with silicone oil or its surface should be roughened. Separation of particles with a micro filter $(\mu \mathrm{F})$ in a $\mu \mathrm{FC}$ in the resonator is limited by the surface of $\mu \mathrm{FC}$ wall, which has to be hydrophobic to let particles pass through without excessive wall loss.

Instead of its inertia as in the case of impactors, differential mobility of charged particles in an electrostatic field is considered in the remainder, which can separate polydisperse particles into several size bins in the diameter range from 50 to $200 \mathrm{~nm}$ (Table 1). This way, a more comprehensive characterization of air quality based on portable DMPS instruments was shown to be feasible [22,23]. Remaining drawbacks of the reported designs are supply voltages in the $\mathrm{kV}$ range needed for both a charging unit and the DMA, a micro pump for air-flow generation, and a sensitive electrometer for particle detection. Furthermore, these instruments are still rather bulky with DMA channel dimensions of $1 \times 5 \times 50 \mathrm{~mm}^{3}$ [22] and a total weight of $1.0 \mathrm{~kg}$ (without battery) and $0.95 \mathrm{~kg}$ of standalone miniature UFP sizers, respectively [22,24].

\section{Microfluidic Channel-Based Mobility-Selective Particle Sizer}

To face the limitations of current portable DMAs, we developed a single-chip MEMS, which consists of a $\mu \mathrm{FC}$ for conducting a particle-laden air flow and an electrostatic field for mobility-selective sampling of the positive-charged fraction on a PMC for gravimetric sensing, which is described in the following.

\subsection{Particle Size Separation Using a Differential Mobility Analyzer}

A DMA is a size-selective charged particle filter, which separates particles of a given mobility from an aerosol flow depending on particle mobility and a tunable applied voltage. If combined with a particle-concentration detector, it is called a DMPS [ISO 15900].

When force on a charged particle in an electrostatic field equals Stokes drag force, its electrical mobility $Z_{p}$ depends on particle radius $d_{p}$ according to [28]:

$$
Z_{\mathrm{p}}=\frac{n q C_{\mathrm{c}}}{3 \pi \eta d_{\mathrm{p}}}
$$

with the number of electrical charges per particle $\mathrm{n}$ and the Cunningham slip correction factor $C_{\mathrm{c}}$ which both depend on $d_{\mathrm{p}}$, the elementary charge $q=1.6 \times 10^{-19} \mathrm{C}$, and the dynamic viscosity of air $\eta=1.8205 \times 10^{-5} \mathrm{~kg} / \mathrm{m} / \mathrm{s}$. For NPs of $d_{\mathrm{p}}=50 \mathrm{~nm}$ we can approximate $n \approx 1$ and $C_{\mathrm{c}} \approx 5$ and calculate a mobility of $Z_{\mathrm{p}} \approx 10^{-7} \mathrm{Cs} / \mathrm{kg}$.

Conventionally, a DMA is arranged in a coaxial tube-wire configuration, i.e., a wire (of radius $r_{1}$ ) in a channel (of radius $R$ ), between which an electrostatic voltage $V_{\text {es }}$ is applied. Along the channel axis, herein, electrically charged particles are carried at a rate $Q$ in a laminar air flow and drift towards the wire or the wall, depending on their electrical 
polarity. Positive-charged particles of diameter $d_{\mathrm{p}}$ and mobility $Z_{\mathrm{P}}$, that enter the channel at a distance $r_{2}$ from the wire axis, can reach a negative-polarized wire after propagating over the length of the tube $L_{\mathrm{ch}}$, if a voltage $V_{\mathrm{es}}$ :

$$
V_{\mathrm{es}}=\frac{Q \ln \left(\frac{r_{2}}{r_{1}}\right)}{2 \pi L_{\mathrm{ch}} Z_{\mathrm{P}}}
$$

is applied.

The separation/sampling efficiency $\xi$ of particles, which enter the tube with uniform size distribution, is given by the ratio of capture cross section to total area of air flow: The capture cross section is the annular area $\pi\left(r_{\mathrm{p}}^{2}-r_{1}^{2}\right)$ defined by the maximum distance $r_{\mathrm{p}}$ from the wire, at which a propagating particle is captured, and the wire radius $r_{1}$. The total area of particle flow can be approximated by the tube cross-sectional area $\left(\pi R^{2}>>\pi r_{1}{ }^{2}\right)$. We thus yield [28]:

$$
\xi\left(V_{\mathrm{es}}, d_{\mathrm{p}}\right) \approx \frac{r_{\mathrm{p}}^{2}-r_{1}^{2}}{R^{2}}=\frac{2}{3 \eta Q} \frac{L_{\mathrm{ch}}}{\ln \left(\frac{R}{r_{1}}\right)} n\left(d_{\mathrm{p}}\right) \mathrm{q} C_{\mathrm{c}}\left(d_{\mathrm{p}}\right) \frac{V_{\mathrm{es}}}{d_{\mathrm{p}}}
$$

In the size range of $d_{\mathrm{p}}=20 \mathrm{~nm}$ to $300 \mathrm{~nm}$, the parameters $\mathrm{n}$ and $C_{\mathrm{c}}$ depend on $d_{\mathrm{p}}$ whereby $C_{\mathrm{c}}$ decreases with $d_{\mathrm{p}}$ while $n$ increases with it. Therefore in total, separation/sampling efficiency will increase with decreasing particle size.

\subsection{Micro-Fluidic Channel with Integrated Piezoresistive Micro Cantilever}

Figure 2 shows a schematic of a $\mu \mathrm{FC}$ with an integrated low-mass PMC resonator for electrostatic separation and sampling of NPs. Charged particles sucked-in at the bottom of the $\mu \mathrm{FC}$ and propagating from different lateral positions of its cross-sectional area can be directed towards the small surface area of the cantilever depending on the acting electrostatic drag force. Owing to the small mass of NPs and the constrictions of air flow in the $\mu \mathrm{FC}$, the device can be operated at low values of separating/sampling voltage $(<150 \mathrm{~V}$ ), flow rate (tens of $\mathrm{mL} / \mathrm{min}$ ) and velocities (tens of $\mathrm{mm} / \mathrm{s}$ ). A small-mass cantilever (16.3 ng) is designed at the top end of the $\mu \mathrm{FC}$ for gravimetric sensing and read-out using a piezoresistive half bridge with resistors represented by released struts extending from the cantilever to the $\mu \mathrm{FC}$ wall. PMC and $\mu \mathrm{FC}$ dimensions are given in Table 2 .

(a)

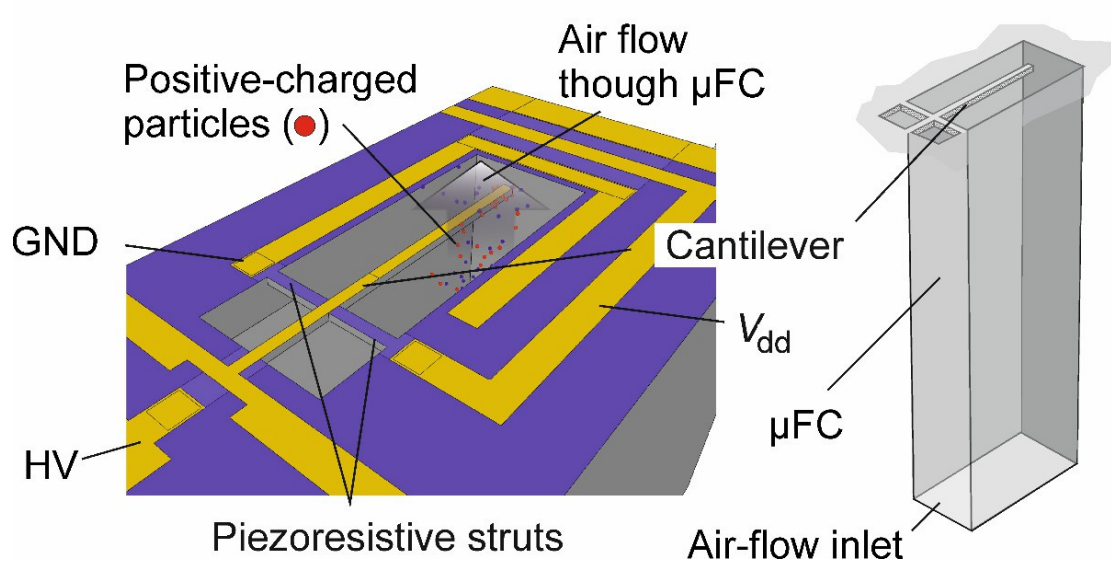

Figure 2. (a) Schematic of a micro cantilever with released piezoresistive struts (as strain gauge supplied by $V_{\mathrm{dd}}$ ) located in a micro-fluidic channel $(\mu \mathrm{FC})$ guiding a particle-laden air flow. The cantilever is negatively polarized using a variable direct current (dc)-voltage (HV) with respect to the $\mu F C$ walls, which are on ground potential (GND). In (b) a schematic of the complete $\mu F C$ is displayed with the air-flow inlet at the bottom of the MEMS die. 
Table 2. Parameters of the piezoresistive micro cantilever (PMC)- $\mu F C(l, w, h$ : length, width, height of the PMC; $L_{\mathrm{ch}}, H_{\mathrm{ch}}$ and $W_{\mathrm{ch}}$ : length, height and width of the $\left.\mu \mathrm{FC}\right)$.

\begin{tabular}{ccccccc}
\hline \multicolumn{4}{c}{ Micro Cantilever } & \multicolumn{3}{c}{ Micro Channel } \\
\hline $\boldsymbol{l}(\boldsymbol{\mu \mathrm { m }})$ & $\boldsymbol{w}(\boldsymbol{\mu \mathrm { m } )}$ & $\boldsymbol{h}(\boldsymbol{\mu \mathrm { m } )}$ & $\boldsymbol{m}_{\mathbf{0}}(\mathbf{n g})$ & $\boldsymbol{L}_{\mathrm{ch}}(\mu \mathrm{m})$ & $\boldsymbol{H}_{\text {ch }}(\mu \mathrm{m})$ & $\boldsymbol{W}_{\text {ch }}(\mu \mathrm{m})$ \\
\hline $171 \pm 1$ & $10.5 \pm 0.4$ & $3.0 \pm 0.5$ & $16.3 \pm 2.9$ & $270 \pm 15$ & $191 \pm 1$ & $72.4 \pm 0.5$ \\
\hline
\end{tabular}

In this design the cantilever resonator acts as the particle-sampling electrode, which is arranged perpendicular to the axis of a rectangular $\mu \mathrm{FC}$ guiding a sucked-in aerosol flow. Finite element modelling (FEM) confirmed that the trajectories of positive-charged particles in a laminar air stream are bent towards the negatively polarized cantilever depending on particle mobility $\left(Z_{\mathrm{p}}\right)$, air-flow rate $(Q)$ and sampling voltage $\left(V_{\mathrm{es}}\right)$.

Fabrication of the PMCs including cantilever, piezoresistive strain gauge, micro-fluidic channel and electrodes for electrostatic particle sampling is based on a novel micromachining process. Its key issue is the underetching of the cantilever without interrupting the cryogenic deep reactive ion etching (cryo DRIE) process. As a consequence, standard bulk silicon wafer material ( $n$-doped, $1-10 \Omega \times \mathrm{cm},<100>$ ) could be used instead of silicon-oninsulator (SOI) wafers, which provides a larger degree of freedom for the design and is less costly. First, thermal diffusion steps are performed for contact formation of the bulk $\left(n^{+}\right)$as well as doping $(p)$ with contact formation $\left(p^{+}\right)$to the piezoresistive struts. Then, a metallization (gold-chromium) is deposited by e-beam evaporation and patterned using lift-off. Finally, the PMC- $\mu \mathrm{FC}$ is fabricated by sequential front-side and back-side cryo DRIE with $\mathrm{SF}_{6}$ and $\mathrm{O}_{2}$ as etch gases. Hereby, the front-side process is further divided into two steps: First, anisotropic etching is performed at an $\mathrm{O}_{2}$ flow rate of $9 \mathrm{sccm}$ to create vertical cantilever and struts sidewalls. Under these conditions a passivation layer is deposited on the sidewalls which remains stable there at the selected cryogenic temperature. Without interrupting the process, i.e., without warming up the wafer, we then lower the $\mathrm{O}_{2}$ flow rate to $4.5 \mathrm{sccm}$ thereby initiating a transition from anisotropy to isotropic etching. After complete release of the cantilever the $\mu \mathrm{FC}$ is then etched from the back side, again under anisotropic etching conditions. Before, photoresist is deposited on the bottom surface of the front-side-etched hole, which then serves as a stop layer for the back-side etching and effectively protects the already released cantilever. Details of the design and fabrication process are available elsewhere $[26,27]$.

In Figure 3a a schematic of the MEMS-based differential mobility particle sizer (MEMSDMPS) is displayed. Here, the MEMS die is mounted upright on a printed circuit board (PCB), which is screwed to a 3D-printed socket with a miniature fan $\left(10 \times 10 \times 2 \mathrm{~mm}^{3}\right.$, HY10A03A, SEPA Europe GmbH, Eschbach, Germany) for intake and flow of air forced through $4 \times 8$ parallel micro-fluidic channels $(\mu \mathrm{FCs})$ in the MEMS die. This sensor PCB is vertically plugged on the main board by pressing it between two mounting brackets. Furthermore, two miniature multilayer piezo linear actuators (PL055.3, PI Ceramic GmbH, Lederhose, Germany) are arranged under force-closure between the PCB and the mounting brackets. The piezo actuators are operated in differential mode for resonant excitation of the sensor PCB with a voltage $V_{\mathrm{ac}}$. The resulting in-plane oscillation of the cantilevers leads to tensile/compressive deformation of the piezoresistive struts $\left(\mathrm{R}^{+} / \mathrm{R}^{-}\right)$, which is read out via an instrumentational amplifier. Figure $3 \mathrm{~b}$ shows a photograph of the sensor PCB with the MEMS die $\left(8 \times 8 \mathrm{~mm}^{2}\right)$ comprising the $4 \times 8$ arrays of piezoresistivemicro-cantilevers in micro-fluidic-channels (PMC- $\mu \mathrm{FC}$ ), which is glued upright onto the sensor PCB $\left(40 \times 40 \mathrm{~mm}^{2}\right)$. The MEMS die is connected to the PCB via soldered $\mathrm{Cu}$ wires. Figure $3 c$ shows a scanning electron microscopy (SEM) photograph of one PMC$\mu \mathrm{FC}$ array including a reference structure, whose electric block diagram is displayed in Figure 3d. Furthermore, the instrumental amplifier (INA217, TI, USA) followed by a Lockin amplifier (MFLI, Zurich Instruments, Zurich, Switzerland) are displayed for read-out of the frequency-dependent amplitude and phase signals as well as the supply ports of 
the excitation voltage $\left(V_{\mathrm{ac}}\right)$ of the piezo actuators, the supply voltage of the piezoresistive strain gauge $\left(V_{\mathrm{dd}}\right)$ and the HV supply.

(a)

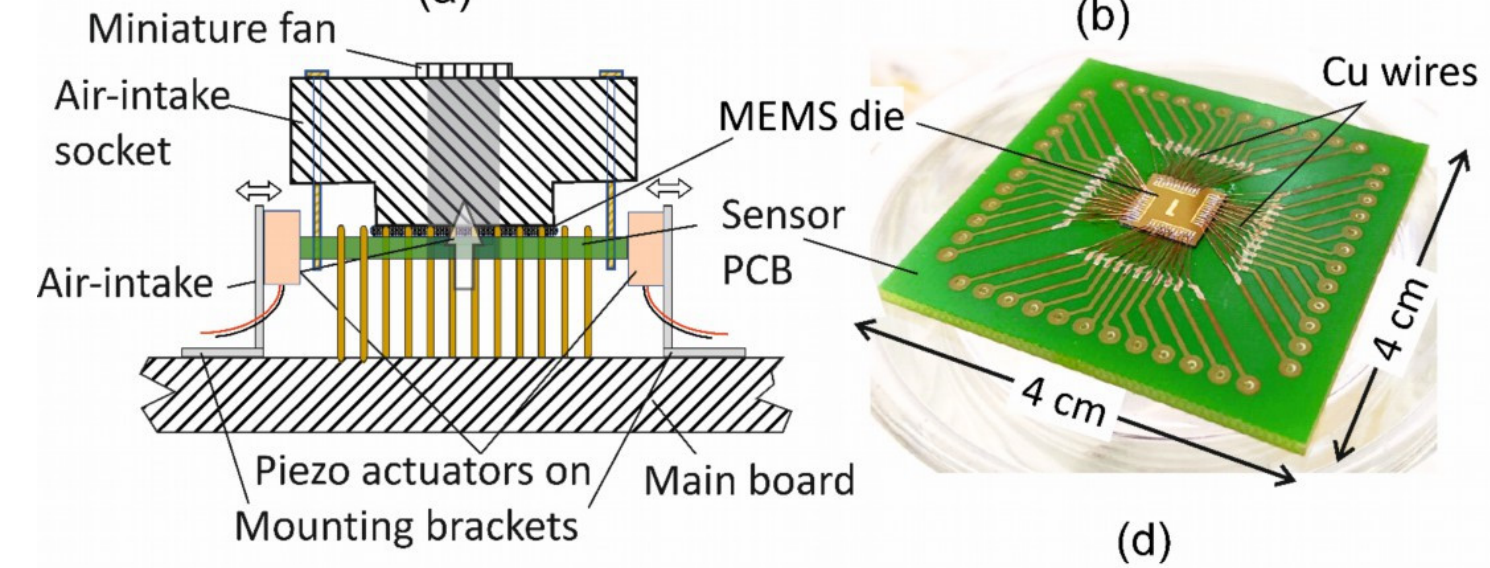

(b)

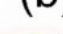

(c)
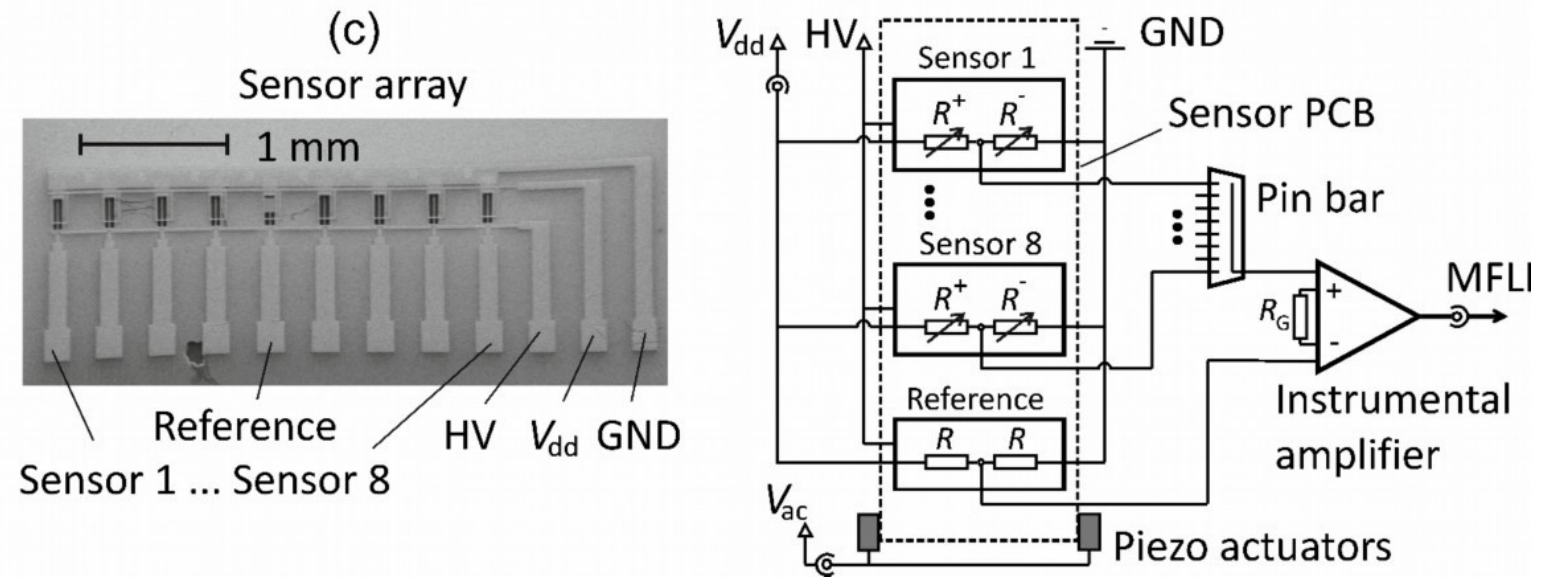

Figure 3. (a) Micro electro mechanical system-differential mobility particle sizer (MEMS-DMPS) with sensor printed circuit board (PCB) vertically plugged between the main board and a 3D-printed air-intake socket with a miniature fan $\left(10 \times 10 \times 2 \mathrm{~mm}^{3}\right.$, HY10A03A, SEPA Europe GmbH, Eschbach, Germany), which provides a bottom-to-top airflow in parallel through $4 \times 8 \mu$ FCs in the MEMS die. The (replaceable) sensor PCB is horizontally pressed in between two miniature multilayer piezo linear actuators (PL055.3, PI Ceramic GmbH, Lederhose, Germany) using mounting brackets connected to the main board. The piezo actuators are operated in differential mode with an excitation voltage $V_{\text {ac. }}$ (b) Photograph of the sensor PCB with the MEMS die $\left(8 \times 8 \mathrm{~mm}^{2}\right)$ glued on a carrier PCB $\left(40 \times 40 \mathrm{~mm}^{2}\right)$ and connected via soldered $\mathrm{Cu}$ wires. (c) Scanning electron microscopy (SEM) photograph of an array of 8 PMC- $\mu$ FCs sensors of identical design, a reference structure and its contact lines to the bridge $\left(V_{\mathrm{dd}}\right)$ and sampling voltage (HV) and ground (GND). (d) Electric block diagram of the sensor PCB with further read-out components and their interconnections on the main board including an instrumental amplifier (INA217, TI, USA) followed by a Lock-in amplifier (MFLI, Zurich Instruments) and BNC connectors for read-out of the measurement signal, the excitation voltage $\left(V_{\mathrm{ac}}\right)$ and $V_{\mathrm{dd}}$ as well as the HV supply pin and GND.

\subsection{Carbon Aerosol Mass-Concentration Measurement}

For sensor testing, a stable test aerosol was generated using a 6-Jet Nebulizer (BGI Inc., Butler, NJ, USA) with a suspension of carbon NPs (<50 nm, Sigma-Aldrich, Taufkirchen, Germany) in isobutanol and deionized (DI) water. The resulting droplets, dried using a diffusion dryer (TSI Inc., Model 3062, Shoreview, MN, USA), were sprayed into a sealed, temperature- and humidity-controlled chamber $\left(23^{\circ} \mathrm{C}, 40 \%\right.$ relative humidity $\left.(\mathrm{RH})\right)$ and circulated therein using a ventilation fan. A laboratory fast mobility particle sizer (FMPS) (5.6-560 nm, 32 size bins, TSI Inc., Model 3091, Shoreview, MN, USA) was used as a reference particle sizing instrument. Figure 4 shows a typical mean size distribution (number and mass concentration) of the nebulized polydisperse carbon aerosol of constant 
mass concentration of $10 \mu \mathrm{g} / \mathrm{m}^{3}$ measured with FMPS over $1 \mathrm{~h}$, which is within the typical range of 4.7 to $19.8 \mu \mathrm{g} / \mathrm{m}^{3}$ of $\mathrm{PM}_{0.1}$ pollution to be monitored and controlled in workplace environments [29].

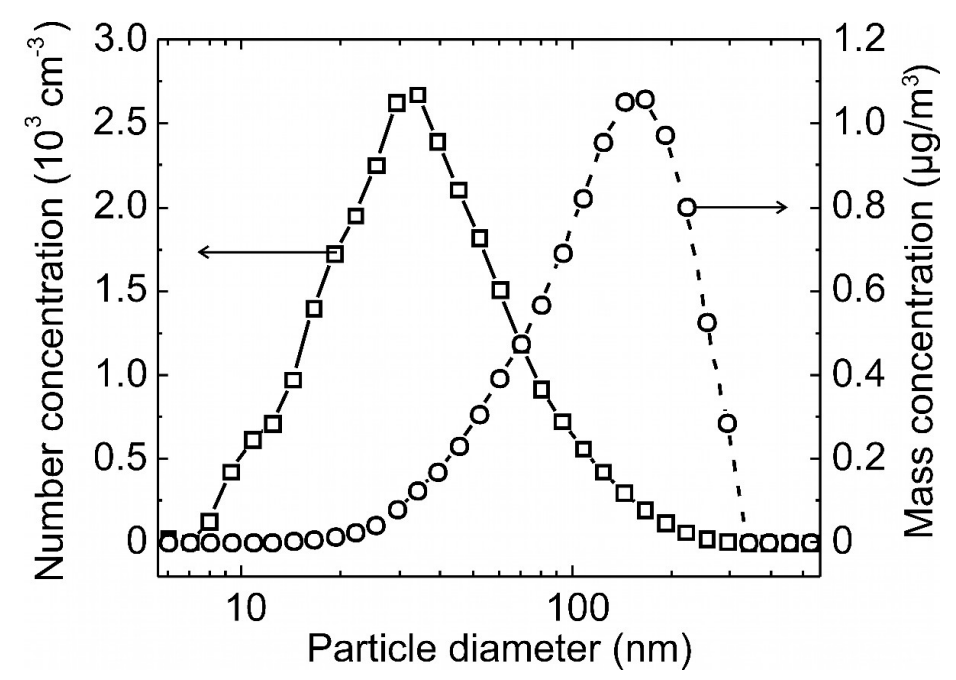

Figure 4. Average size distribution of a nebulized polydisperse carbon aerosol measured with fast mobility particle sizer (FMPS).

The size distribution of average particle number concentration $c_{\mathrm{n}}$ of the nebulized poly-disperse carbon aerosol in Figure 4 shows a single-size mode with a maximum at $d_{\mathrm{p}} \approx 30 \mathrm{~nm}$, from which mass concentrations $c_{\mathrm{m}}$ were calculated assuming spherical shape and uniform density of $\rho_{\text {carbon }}=2.26 \mathrm{~g} / \mathrm{cm}^{3}$ of the particles:

$$
c_{\mathrm{m}}\left(\text { in } \frac{\mu \mathrm{g}}{\mathrm{m}^{3}}\right)=10^{9} \times \frac{\pi}{6} \rho_{\text {carbon }}\left(\text { in } \frac{\mathrm{kg}}{\mathrm{m}^{3}}\right) \times d_{\mathrm{p}}^{3}\left(\text { in } \mathrm{cm}^{3}\right) \times c_{\mathrm{n}}\left(\text { in } \frac{\#}{\mathrm{~cm}^{3}}\right) .
$$

Here, the maximum of the size distribution has shifted towards a larger diameter of $d_{\mathrm{p}} \approx 150 \mathrm{~nm}$ due to the cubic dependence of particle mass on the diameter $\left(\sim d_{\mathrm{p}}{ }^{3}\right)$, which leads to a larger contribution of the bigger particle fraction to $c_{\mathrm{m}}$ compared to $c_{\mathrm{n}}$.

Synchronized with the FMPS, one of the PMC- $\mu$ FCs of the MEMS-DMPS (see Figure 3) was operated in the aerosol chamber. The selected operating parameters are given in Table 3.

Table 3. Operating parameters of the PMC- $\mu \mathrm{FC}$ with carbon NPs ( $c_{\mathrm{m}}$ : particle mass concentration; $\mathrm{Q}$ : air-flow rate; $f_{0}$ : cantilever resonance frequency; $m_{0}$ : cantilever mass; $t_{\mathrm{s}}$ : sampling time).

\begin{tabular}{ccccc}
\hline$c_{\mathrm{m}}\left(\mu \mathrm{g} / \mathrm{m}^{3}\right)$ & $Q(\mu \mathrm{L} / \mathbf{m i n}) ;\left(\mathbf{1 0}^{-\mathbf{9}} \mathbf{m}^{\mathbf{3}} / \mathbf{s}\right)$ & $f_{0}(\mathbf{k H z})$ & $V_{\text {es }}(\mathrm{V})$ & $t_{s}(\mathbf{m i n})$ \\
\hline $10 \pm 1$ & $306 \pm 30 ; 5.1 \pm 0.5$ & $400 \pm 5$ & -5 to -30 & 9.5 \\
\hline
\end{tabular}

Figure 5 shows SEM images of a PMC with $\mu \mathrm{FC}$ and a reference structure represented by a not-released cantilever without $\mu \mathrm{FC}$. Particle separation/sampling and sensing was undertaken simultaneously, i.e., the PMC was connected to the HV supply for setting-up the electrostatic field while resonance frequency of cantilever was measured by frequency sweeps [27]. Carbon NPs captured during separation/sampling are clearly visible in the SEM images of the PMC in Figure 5 taken at the end of the measurement run, whereas they do not appear on the reference structure.

The measured frequency shift rate at $c_{\mathrm{m}}=10 \mu \mathrm{g} / \mathrm{m}^{3}$ and $V_{\mathrm{es}}=-30 \mathrm{~V}$ amounts to $4.7 \pm 0.5 \mathrm{~Hz} / \mathrm{min}$. The LOD is $0.75 \mu \mathrm{g} / \mathrm{m}^{3}$. Inherent fluctuations of particle size distribution in small sample volumes may have caused the measured uncertainty of frequency shift rate of $\sim 10 \%$. At our sampling time of $t_{\mathrm{s}}=9.5 \mathrm{~min}$ and an air flow rate of $Q=0.3 \mathrm{~mL} / \mathrm{min}$, 
we have a sample volume of vs. $\sim 3 \mathrm{~mL}$, which at the measured concentration of $10 \mu \mathrm{g} / \mathrm{m}^{3}$ corresponds to a total particle mass in the sample of $\sim 30 \mathrm{pg}$. In agreement with our finding, a $10 \%$ uncertainty can be expected at a total sample mass of $30 \mathrm{pg}$ according to model calculations for $\mathrm{PM}_{1}[30]$.
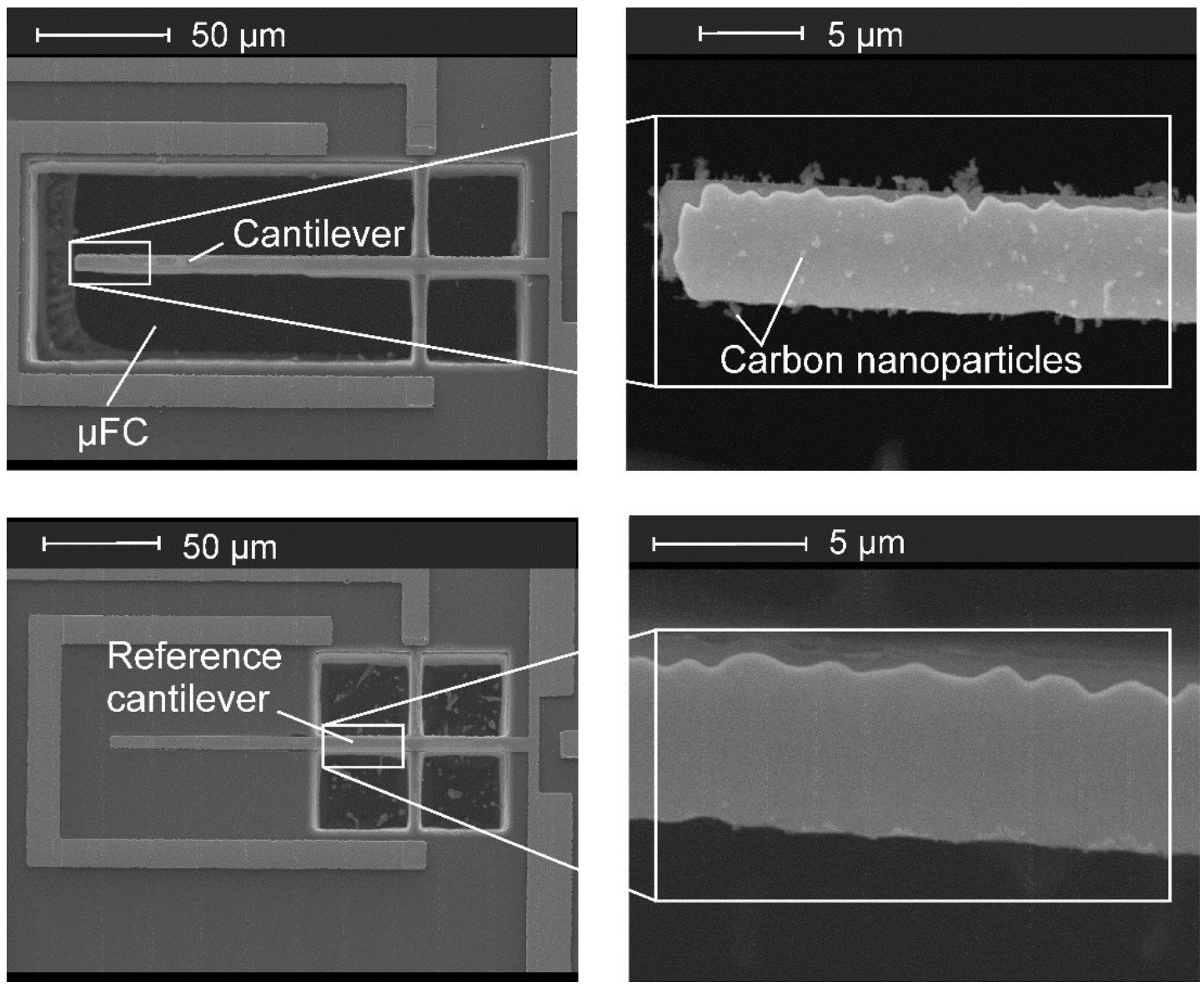

Figure 5. Scanning electron micrograph (SEM) of a PMC- $\mu$ FC after carbon aerosol particles sampling using $V_{\mathrm{es}}=-30 \mathrm{~V}$ at a mass concentration in the chamber of $10 \mu \mathrm{g} / \mathrm{m}^{3}$ for $1 \mathrm{~h}$. Sampled carbon NPs are visible only on the cantilever in a free-etched $\mu \mathrm{FC}$ (upper), while the reference structure without $\mu \mathrm{FC}$ does not show any precipitated particle (lower).

\section{Aerosol Particle Sizing Using the Micro Electro Mechanical System-Differential Mobility Particle Sizer (MEMS-DMPS)}

\subsection{Electrostatic Particle Separation}

The PMC- $\mu$ FC device in Figure 2 can be operated as a DMA for which according to Equation (3), the number of captured particles increases with the sampling voltage and via its size with electrical particle mobility. For confirmation, we performed FEM using COMSOL Multiphysics showing that at sampling/separation voltages of $-4 \mathrm{~V},-26 \mathrm{~V}$ and $-140 \mathrm{~V}$ positive-charged NPs of diameters of $5 \mathrm{~nm}, 50 \mathrm{~nm}$ and $2.5 \mu \mathrm{m}$, respectively, selectively precipitate on the cantilever with maximum efficiencies of nearly $60 \%$ to $80 \%$ [26]. With its ability to detect sampled particle size bins on a cantilever balance, we can consider this device as a MEMS-DMPS with the resonance-frequency shift rate of the PMC as output signal.

The sampling efficiency $\xi\left(V_{\mathrm{es}}, d_{\mathrm{p}}\right)$, which is necessary for retrieving the size-distribution of mass concentration of an aerosol from a measured voltage dependence of frequency-shift rate can be determined if the distribution of the number of electrical charges per particle $n$ is known [31]. Conventionally, for this purpose aerosol samples with Boltzmann and unipolar charge distributions are prepared. A radioactive source as diffusion neutralizer or a unipolar corona charger are used [32] which, however, are accompanied by a possible 
excessive mobility overlap between different size bins due to multiple charging in case of unipolar diffusion charging [31].

Instead, in this study, we dispense with an additional charging unit and sample only the naturally positive-charged aerosol fraction. As a quantitative measure of the charging state of a naturally charged aerosol we adopt the size and charge distributions measured in the range of $d_{\mathrm{p}}=20 \mathrm{~nm}$ to $400 \mathrm{~nm}$ with a $\mathrm{NaCl}$ aerosol [33], which we consider as a model system for aerosol charge distributions generated by a nebulizer. We assume that this non-equilibrium charge distribution can describe not only $\mathrm{NaCl}$ but also other nebulized aerosols with sufficient accuracy even if, in general, the charge distribution may be dependent on the specific aerosol nebulizer configuration and the chemical composition of the nebulized solution. In the following, we describe a method based on $\xi\left(V_{\mathrm{es}}, d_{\mathrm{p}}\right)$ determined accordingly (cf. Appendices A and B), which we propose for retrieving the size-distribution of nebulized aerosols from measurements with the MEMS-DPMS.

Particle sampling on a cantilever resonator yields a resonance-frequency shift rate of $[13,25]$ :

$$
\frac{\Delta f}{\Delta t}\left(V_{\mathrm{es}}, d_{\mathrm{p}}\right)=\frac{f_{0}}{2 m_{0}} \frac{\Delta m}{\Delta t}=\frac{f_{0}}{2 m_{0}} \frac{\Delta t}{\Delta V} \frac{\Delta V}{\Delta t} \frac{\Delta m}{\Delta t}=\frac{f_{0}}{2 m_{0}} \frac{V_{\mathrm{s}}}{t_{\mathrm{s}}} \frac{\Delta m}{\Delta V}=\frac{f_{0}}{2 m_{0}} Q \xi\left(V_{\mathrm{es}}, d_{\mathrm{p}}\right) c_{\mathrm{m}}
$$

with the particle mass concentration $c_{\mathrm{m}}$, the air flow rate $Q=V_{\mathrm{s}} / t_{\mathrm{s}}$, the sample volume $V_{\mathrm{s}}$, the sampling time $t_{\mathrm{s}}$, the resonance frequency $f_{0}$ and the resonator mass $m_{0}$. The frequency shift rate depends via the separation/sampling efficiency $\xi\left(V_{\mathrm{es}}, d_{\mathrm{p}}\right)$ on the applied voltage $V_{\mathrm{es}}$ between the cantilever and the $\mu \mathrm{FC}$ wall as well as on the particle's diameter $d_{\mathrm{p}}$ (cf. Equation (3)). Here we consider ranges of particle size and sampling voltage separated in $u$ size bins, i.e., $l=1, \ldots, u$ and voltage steps, i.e., $k=1, \ldots, v$ with $v \geq u$, respectively, define $\xi_{\mathrm{kl}}\left(V_{\mathrm{es}, \mathrm{k}}, d_{\mathrm{p}, 1}\right)$ as the efficiency for capturing particles of the $l$-th size bin at the $k$-th sampling voltage and replace Equation (5) by a matrix equation:

$$
\left(\begin{array}{c}
{[\Delta f / \Delta t]_{1}} \\
\vdots \\
{[\Delta f / \Delta t]_{v}}
\end{array}\right)=\frac{f_{0}}{2 m_{0}} Q\left(\begin{array}{ccc}
\xi_{11} & \cdots & \xi_{1 u} \\
\vdots & \ddots & \vdots \\
\xi_{v 1} & \cdots & \xi_{v u}
\end{array}\right)\left(\begin{array}{c}
c_{m, 1} \\
\vdots \\
c_{m, u}
\end{array}\right)
$$

The vector of mass concentrations $\left(c_{\mathrm{m}, 1}\right)$ (represented by the $u$ size bins of $l=1, \ldots, u$ ) is multiplied by the efficiency matrix $\xi_{\mathrm{kl}}\left(V_{\mathrm{es}, \mathrm{k}}, d_{\mathrm{p}, 1}\right)$ and thus is transformed to a vector of frequency-shift rates $\left([\Delta f / \Delta t]_{\mathrm{k}}\right)$ (represented by the $v$ voltage values of $k=1, \ldots, v$ with $v \geq u$ ).

We use FEM to determine $\xi_{\mathrm{kl}}\left(V_{\mathrm{es}, \mathrm{k}}, d_{\mathrm{p}, 1}\right)$ assuming a uniform distribution of particle size across the $\mu \mathrm{FC}$ cross-section area at the position, where the air flow enters the $\mu \mathrm{FC}$ (cf. Appendix B). For the size range of the polydisperse aerosol we take 20 to $500 \mathrm{~nm}$ [23] and separate it into $u=6$ size bins, which we set according to the 24 bins of a standard FMPS reference instrument as defined in Table A4, and represent them by mean diameters of $d_{\mathrm{p}, 1}=24.1 \mathrm{~nm}, 43.2 \mathrm{~nm}, 77.3 \mathrm{~nm}, 138.0 \mathrm{~nm}, 245.9 \mathrm{~nm}, 437.7 \mathrm{~nm}$ for $l=1, \ldots, 6$. The elements of the $6 \times 6$ efficiency matrix in Equation (6) are obtained by averaging the respective elements of the $6 \times 24$ efficiency matrix in Equation (A1):

$$
\left(\begin{array}{ccc}
\xi_{11} & \cdots & \xi_{16} \\
\vdots & \ddots & \vdots \\
\xi_{61} & \cdots & \xi_{66}
\end{array}\right)=\left(\begin{array}{cccccc}
0.021 & 0.028 & 0.033 & 0.025 & 0.021 & 0.015 \\
0.034 & 0.5 & 0.047 & 0.042 & 0.033 & 0.021 \\
0.061 & 0.08 & 0.093 & 0.077 & 0.049 & 0.028 \\
0.1 & 0.161 & 0.175 & 0.147 & 0.099 & 0.052 \\
0.109 & 0.225 & 0.299 & 0.273 & 0.186 & 0.085 \\
0.111 & 0.227 & 0.325 & 0.365 & 0.307 & 0.162
\end{array}\right)
$$

As expected from Equation (3) the values of the efficiency matrix in Equation (7) show a trend towards larger values with increasing applied voltage for all size bins (i.e., each 
column). For each voltage, maximum efficiencies are found for a medium bin size of around $100 \mathrm{~nm}$. The maximum value of $\xi=36.5 \%$ nearly corresponds to the expected fraction of positive-charged particles of $\approx 40 \%$ in a nebulized $\mathrm{NaCl}$ aerosol (see Appendix A) indicating that almost all positive-charged particles of $d_{\mathrm{p}}=100 \mathrm{~nm}$ were sampled at the highest $V_{\text {es }}$. The decrease of efficiency with increasing particle size above $100 \mathrm{~nm}$ can be expected according to Equation (3). Due their larger inertia, the trajectories of such larger particles will not be sufficiently bent towards the cantilever to be captured there. The visible efficiency drop for small-size particles reflects the remarkably smaller positive-charged fraction of particles of $d_{\mathrm{p}}<100 \mathrm{~nm}$ and can also be related to particle loss by diffusion or Brownian motion to the channel wall.

\subsection{Carbon Particle Sizing Using the MEMS-DMPS}

We measured the frequency shift rate $\Delta f / \Delta t$ of our MEMS-DMPS at sampling voltages $V_{\text {es }}$ that varied from $-30 \mathrm{~V}$ to 0 and from 0 to $-25 \mathrm{~V}$ with carbon UFPs of a constant mass concentration of $10 \mu \mathrm{g} / \mathrm{m}^{3}$ and polydisperse size distribution (see Figure 4). With the MEMS-DMPS, each $\Delta f / \Delta t$ value was determined from the frequency-shift measured after sampling times of $t_{\mathrm{s}}=9.5 \mathrm{~min}$ by averaging over 15 times repeated frequency sweeps. In Figure 6 these measured values are compared with $\frac{\Delta f}{\Delta t}\left(V_{\mathrm{es}}\right)$ according to Equation (A8) from FEM. Reasonable agreement is visible for small sampling voltages $V_{\text {es }} \leq \mid-15 \mathrm{VI}$. Above this range, FEM shows a flatter dependence on $V_{\text {es }}$ than expected from the experiment. As a possible reason for this, differences in charge distribution between the reference aerosol $(\mathrm{NaCl})$ and carbon may be considered. Furthermore, the capture cross-section, i.e., the maximum distance $r_{p}$ at which a propagating particle will be captured on the wire, depends on the electrical field around the wire, which is not considered in the modelling. An increase of $r_{\mathrm{p}}$ can be expected at increasing voltage $V_{\mathrm{es}}$, which corresponds to a larger cross-section than expected and may lead to the larger frequency-shift rate visible in the experiment.

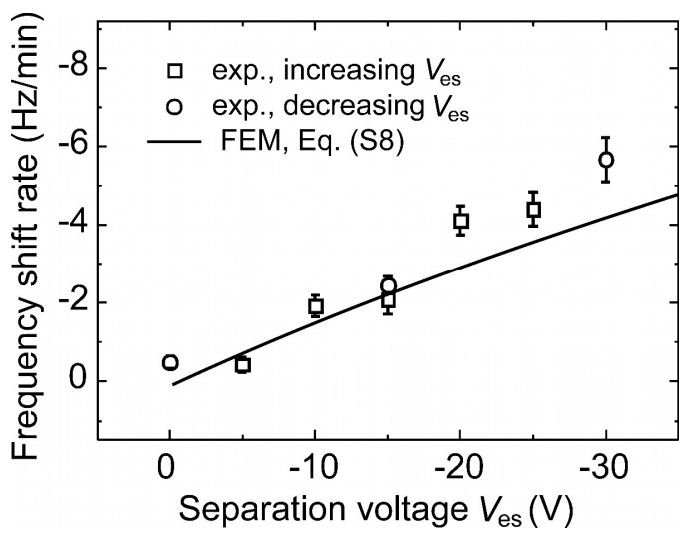

Figure 6. Frequency-shift rate and calculated curve using Equation (A8) from finite element modelling (FEM) measured at different sampling voltages.

For retrieving the size distribution of the considered carbon aerosol, Equation (6) was used to transform the given vector of frequency shift rates $\left([\Delta f / \Delta t]_{\mathrm{k}}\right)$ (with $\left.k=1, \ldots, v\right)$ at $V_{\mathrm{es}}=-5 \mathrm{~V},-10 \mathrm{~V},-15 \mathrm{~V},-20 \mathrm{~V},-25 \mathrm{~V}$, and $-30 \mathrm{~V}$ (FEM values in Figure A2) back into a vector of mass concentrations $c_{\mathrm{m}, 1}(l=1, \ldots, u)$ at $d_{\mathrm{p}, 1}=24.1 \mathrm{~nm}, 43.2 \mathrm{~nm}, 77.3 \mathrm{~nm}$, $138.0 \mathrm{~nm}, 245.9 \mathrm{~nm}$, and $437.7 \mathrm{~nm}$. For this, the system of six equations (corresponding to Equation (6)):

$$
\left[\frac{\Delta f}{\Delta t}\right]_{\mathrm{k}}=\frac{f_{0}}{2 m_{0}} Q \frac{\Delta m}{\Delta t} \sum_{\mathrm{l}=1}^{\mathrm{u}} \xi_{\mathrm{kl}} c_{\mathrm{m}, \mathrm{l}} ; k=1, \ldots, v
$$

was solved using the approximation method of the non-negative least squares in MatLab (Isqnonneg()). The results are plotted in Figure 7 superimposed to the size distribution measured using FMPS in the original 24 size bins as well as after compression into the 
6 bins of the MEMS-DMPS. The corresponding number concentrations were recalculated from the mass concentrations according to Equation (4). We find good agreement within the entire size range except the smallest bin of $d_{\mathrm{p}, 1}=24.1 \mathrm{~nm}$, where a zero concentration value was obtained with the FEM data of the MEMS-DMPS. Here, a mass concentration of $0.16 \mu \mathrm{g} / \mathrm{m}^{3}\left(c_{\mathrm{n}, 1}=8.6 \times 10^{3} \mathrm{~cm}^{-3}\right)$ was found by FMPS, which is far below the LOD of the MEMS-DMPS of $0.73 \mu \mathrm{g} / \mathrm{m}^{3}$. For the next bin of $d_{\mathrm{p}, 2}=43.2 \mathrm{~nm}$, where we have a mass concentration of $0.84 \mathrm{\mu g} / \mathrm{m}^{3}\left(c_{\mathrm{n}, 2}=9.0 \times 10^{3} \mathrm{~cm}^{-3}\right)$ according to the FMPS, the MEMS-DMPS yields $0.97 \mu \mathrm{g} / \mathrm{m}^{3}\left(c_{\mathrm{n}, 2}=10.1 \times 10^{3} \mathrm{~cm}^{-3}\right)$, which is in quite good agreement of $12 \%(15 \%)$.

(a)

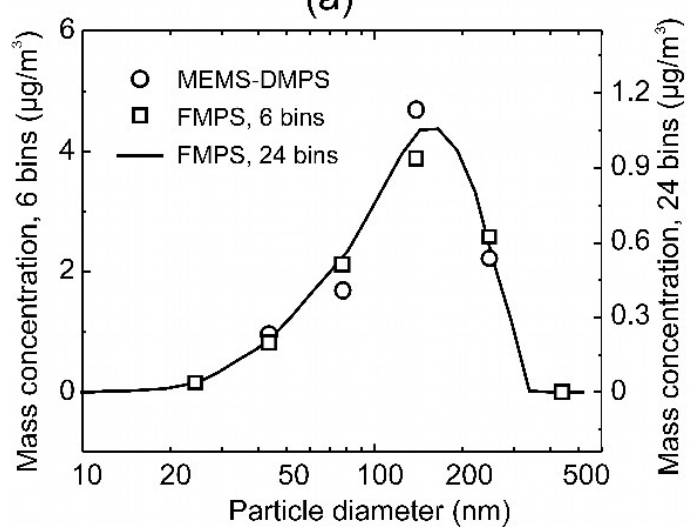

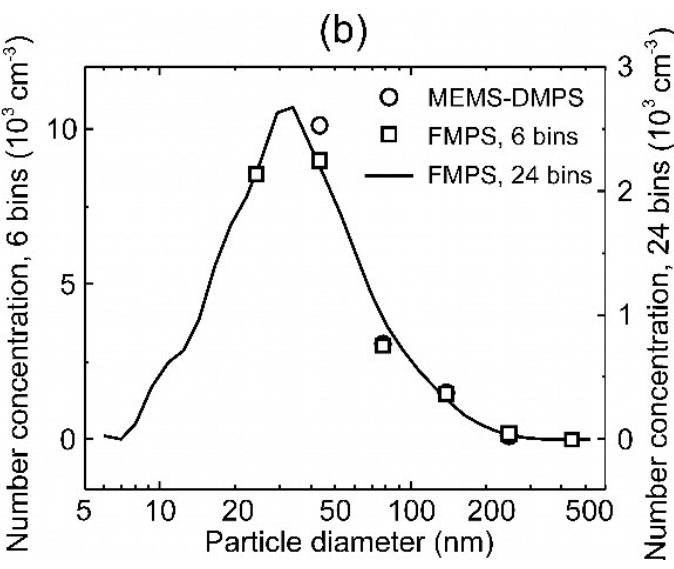

Figure 7. Size distributions of mass (a) and number $(\mathbf{b})$ concentrations of a nebulized polydisperse carbon aerosol determined for the novel MEMS-DMPS vs. the values measured by FMPS.

From the number concentrations, we can calculate the amount of sampled NPs by the MEMS-DMPS for each considered diameter bin from the sucked-in air volume of vs. $\approx 3 \mu \mathrm{L}$ at an air flow rate $Q \approx 0.3 \mu \mathrm{L} / \mathrm{min}$ and a sampling time $t_{\mathrm{s}}=9.5 \mathrm{~min}$. We find total particle numbers ranging from $\approx 30,000$ particles for the bin of the smallest diameters $\left(l=2, d_{\mathrm{p}}=43.2 \mathrm{~nm}\right)$ to 366 particles for the bin of the largest diameters $(l=5$, $d_{\mathrm{p}}=249.9 \mathrm{~nm}$ ), which cause statistical errors ranging from $0.6 \%$ to $5.2 \%$, respectively.

Figure 8 shows a correlation plot of the mass and number concentrations obtained by FEM with the MEMS-DMPS vs. the values measured by FMPS, indicating small maximum deviations of less than $13.6 \%$ and $11.1 \%$ for mass and number concentration, respectively.

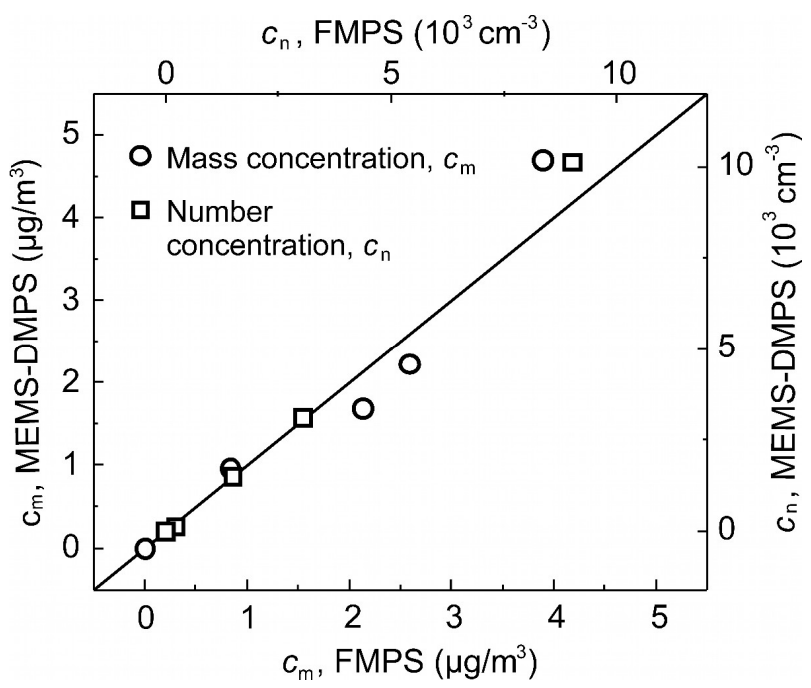

Figure 8. Correlation plot of mass concentration $c_{\mathrm{m}}$ and number concentration $c_{\mathrm{n}}$ of a nebulized poly-disperse carbon aerosol determined for the MEMS-DMPS in six size bins vs. the measured FMPS values. 


\section{Regeneration of the MEMS-DMPS}

For continuous use, sampling-based particle monitors/sizers need periodical refreshing by removing the deposited particles from the sampling body or exchanging it for a clean one. In the case of gravimetric detection, the chip containing the resonant device would have to be discarded, which in our case was the MEMS-DMPS chip. To avoid this, cleaning methods of the PMC were proposed and investigated. For removing NPs from a surface, the strong adhesive force acting on the particle has to be surmounted. This can be accomplished with an efficiency of nearly $100 \%$ in liquid solvent under the assistance of ultrasonic agitation [34]. Alternatively, a carbon dioxide snow jet can be used to dislodge particles by the impact of solid ice sprayed to the resonator surface under small angle of incidence [35]. Since these methods usually require de-mounting of the sensing chip from its package, it will not be practicable for an unskilled end user.

Adhesion force increases linearly with diameter, while drag force acting on particles in an air flow is proportional to $d_{\mathrm{p}}{ }^{2}$. Therefore, NPs are much more difficult to remove than large particulates. However, strong adhesion may cause NPs to agglomerate into larger deposits (Figure 5). For daily cleaning, it might thus be sufficient to remove those excessive deposits of large agglomerates by purging clean air through the sampling head, for which the drag force by the air flow can overcome adhesion. In addition, adhesive forces on the NPs can be considerably lowered by a solvent condensed onto the cantilever surface, e.g., from an acetone steam, as shown recently with the PMC of the portable Cantor instrument [25].

To check this approach, we investigated a PMC loaded with excessive particulate deposits. We only unplugged the sampling unit from the main board, without de-mounting the sensor PCB from the air-intake socket. Then, we fixed it air-tight on a box containing a reservoir of acetone and switched the fan on to let the acetone steam purge around the PMC and condense there for $10 \mathrm{~min}$. After separating the sensor PCB from the acetone steam, we allowed particles to be removed with the evaporating acetone within a further $5 \mathrm{~min}$ in a forced clean-air flow, i.e., with the fan switched on. For confirmation of the refreshing, we re-mounted the sensor PCB to the main board and measured resonance-frequency shift and corresponding mass loss. By repeating this procedure four times, we observed a regeneration of the cantilever indicated by a positive frequency shift rate of $8.7 \mathrm{~Hz} / \mathrm{min}$ corresponding to a mass removal rate of $\approx 0.7 \mathrm{pg} / \mathrm{min}$. An extension of the purging time in acetone did not further accelerate particle removal. Thus, about $43 \mathrm{~min}$ will be necessary to remove a total of $30 \mathrm{pg}$ deposited mass from a $1 \mathrm{~h}$ operation in $10 \mu \mathrm{g} / \mathrm{m}^{3}$ aerosol (see Figure 5). Nevertheless, further experiments, e.g., with other solvents and varied times and flow rates of clean-air purging, will be necessary to improve the refreshing characteristics of cantilevers.

\section{Conclusions}

A differential mobility ultrafine particle (UFP) sizer was described based on a resonant piezoresistive micro cantilever (PMC) in a micro-fluidic channel $(\mu \mathrm{FC})$ integrated as a differential mobility particle sizer in a single-chip microelectromechanical system (MEMS-DMPS). Sizing of a carbon nanoparticles aerosol was shown by electrostatic mobility separation of the positive-charged fraction in the $\mu \mathrm{FC}$ and capturing them on the PMC. An inversion method was described based on a priori known charge distribution of the nebulized carbon aerosol combined with finite element modelling (FEM) for retrieving particle size in four bins between $\sim 40 \mathrm{~nm}$ and $\sim 250 \mathrm{~nm}$. Mass concentrations in the range of $0-5 \mu \mathrm{g} / \mathrm{cm}^{3}$ showed good agreement of better than $14 \%$ of the novel MEMS-DMPS and was found with a simultaneously operated standard reference instrument. The new device offers some advantages vs. electrometer-based micro-fluidic UFP sizers for mobile operation, e.g., an order of magnitude lower separation/sampling voltage and a noiseless miniature fan for air suction. One-chip integration of separating/sampling/detecting components in a standard bulk silicon wafer is a further benefit with respect to reliability and high-volume manufacturing. Polluted cantilevers can be refreshed without de-mounting from a package 
by purging them alternately in acetone steam and clean air. For a MEMS-based fast mobility particle sizer (MEMS-FMPS) an array of 8 micro channels and cantilever resonators can be operated in parallel at a different fixed sampling voltage for each element in the range of $-20 \mathrm{~V}$ to $-160 \mathrm{~V}$, which will be addressed in a future work.

Author Contributions: Conceptualization, M.B. and E.P.; methodology, M.B.; software, M.B.; validation, M.B. and E.P.; formal analysis, M.B.; investigation, M.B. and I.K.; resources, E.U. and E.P.; data curation, M.B.; writing —original draft preparation, E.P.; writing—review and editing, M.B., E.U. and E.P.; visualization, M.B.; supervision, E.U. and E.P.; project administration, E.P.; funding acquisition, E.P. All authors have read and agreed to the published version of the manuscript.

Funding: This research was funded by Niedersächsiches Vorab, Lower Saxony, Germany through the Quantum- and Nanometrology (QUANOMET) initiative within project NP 2-2. The APC was funded by TU Braunschweig.

Institutional Review Board Statement: Not applicable.

Informed Consent Statement: Not applicable.

Data Availability Statement: Not applicable.

Acknowledgments: We are grateful to Quang Duc Pham, Lukas Eisele, Aileen Michalski, Juliane Breitfelder, Angelika Schmidt and Karl-Heinz Lachmund for their valuable technical support. We acknowledge support by the German Research Foundation and the Open Access Publication Funds of Technische Universität Braunschweig.

Conflicts of Interest: The authors declare no conflict of interest.

\section{Appendix A. Positive-Charged Fraction of Nebulized Aerosol}

Measured fractions $n_{\mathrm{p}}^{+}\left(d_{\mathrm{p}}, n\right)$ of $n$-times $(n=1,2,3,4,5,6)$ positive-charged particles with diameters of $d_{\mathrm{p}}=20 \mathrm{~nm}, 30 \mathrm{~nm}, 70 \mathrm{~nm}, 100 \mathrm{~nm}, 200 \mathrm{~nm}$, and $400 \mathrm{~nm}$ are given in reference [33] for a $\mathrm{NaCl}$ aerosol generated by a nebuliser (Table A1). Values for $n=5,6$ are determined by extrapolation.

Table A1. Fraction $n_{\mathrm{p}}^{+}\left(d_{\mathrm{p}}\right)$ of $n$-times positive-charged particles of a nebulized $\mathrm{NaCl}$ aerosol (data of Simones et al. [33], Figure 4) for particle diameters $d_{\mathrm{p}}$ (values for $n=5$ und $n=6$ were estimated by extrapolation of the charge distribution).

\begin{tabular}{cccccccc}
\hline $\boldsymbol{n}$ & \multicolumn{7}{c}{$\boldsymbol{n}_{\mathbf{p}}^{+}\left(\boldsymbol{d}_{\mathbf{p}}, \boldsymbol{n}\right)$} \\
\cline { 2 - 8 } & $\boldsymbol{d}_{\mathbf{p}} \mathbf{( n m ) = 2 0}$ & $\mathbf{3 0}$ & $\mathbf{4 0}$ & $\mathbf{7 0}$ & $\mathbf{1 0 0}$ & $\mathbf{2 0 0}$ & $\mathbf{4 0 0}$ \\
\hline 1 & 0.08 & 0.16 & 0.19 & 0.21 & 0.185 & 0.12 & 0.05 \\
2 & 0.004 & 0.019 & 0.042 & 0.097 & 0.12 & 0.092 & 0.06 \\
3 & & 0.0014 & 0.0066 & 0.034 & 0.056 & 0.076 & 0.06 \\
4 & & & 0.0013 & 0.012 & 0.027 & 0.052 & 0.048 \\
5 & & & & 0.0035 & 0.014 & 0.0353 & 0.033 \\
6 & & & & & & 0.0189 & 0.0214 \\
\hline
\end{tabular}

From this we then calculate the average number of elementary charges of the positivecharged particle fraction for each particle diameter:

$$
\overline{q_{\mathrm{p}}^{+}}\left(d_{\mathrm{p}}\right)=\frac{\sum_{n=1}^{6} n \times n_{\mathrm{p}}^{+}\left(d_{\mathrm{p}}, n\right)}{\overline{n_{\mathrm{p}}^{+}}\left(d_{\mathrm{p}}, n\right)}
$$

with the corresponding normalized number of positive-charged particles (positive-charged fraction of the particles of the aerosol):

$$
\overline{n_{\mathrm{p}}^{+}}\left(d_{\mathrm{p}}\right)=\sum_{n=1}^{6} n_{\mathrm{p}}^{+}\left(d_{\mathrm{p}}, n\right)
$$



Table A2.

The values of $\overline{n_{\mathrm{p}}^{+}}$and $\overline{q_{\mathrm{p}}^{+}}$for particle diameters $d_{\mathrm{p}}$ from $20 \mathrm{~nm}$ to $400 \mathrm{~nm}$ are given in

Table A2. From the values in Table A1 calculated average normalized fraction of positive-charged particles $\overline{n_{\mathrm{p}}^{+}}\left(d_{\mathrm{p}}\right)$ and their average charge number $\overline{q_{\mathrm{p}}^{+}}\left(d_{\mathrm{p}}\right)$.

\begin{tabular}{cccccccc}
\hline$d_{\mathrm{p}}(\mathbf{n m})$ & $\mathbf{2 0}$ & $\mathbf{3 0}$ & $\mathbf{4 0}$ & $\mathbf{7 0}$ & $\mathbf{1 0 0}$ & $\mathbf{2 0 0}$ & $\mathbf{4 0 0}$ \\
\hline$\overline{n_{p}^{+}}$ & 0.084 & 0.1804 & 0.2399 & 0.3565 & 0.402 & 0.3942 & 0.2724 \\
$\overline{\boldsymbol{q}_{p}^{+}}$ & 1.04 & 1.12 & 1.25 & 1.6 & 1.92 & 2.61 & 3.07 \\
\hline
\end{tabular}

In Figure A1 the values of $\overline{n_{\mathrm{p}}^{+}}$and $\overline{q_{\mathrm{p}}^{+}}$given in Table $\mathrm{A} 2$ are plotted vs. $d_{\mathrm{p}}$ and superimposed with curves respectively fitted using a polynomial function:

$$
y_{1}\left(d_{\mathrm{p}}\right)=\frac{a_{1} d_{\mathrm{p}}^{2}+a_{2} d_{\mathrm{p}}+a_{3}}{d_{\mathrm{p}}^{2}+b_{1} d_{\mathrm{p}}+b_{2}}
$$

We find average charge numbers between about 1 and 3 and positive-charged fraction between about 0.1 and 0.4. The fitting parameters $a_{1}, a_{2}, a_{3}, b_{1}$ and $b_{2}$ are shown in Table A3.

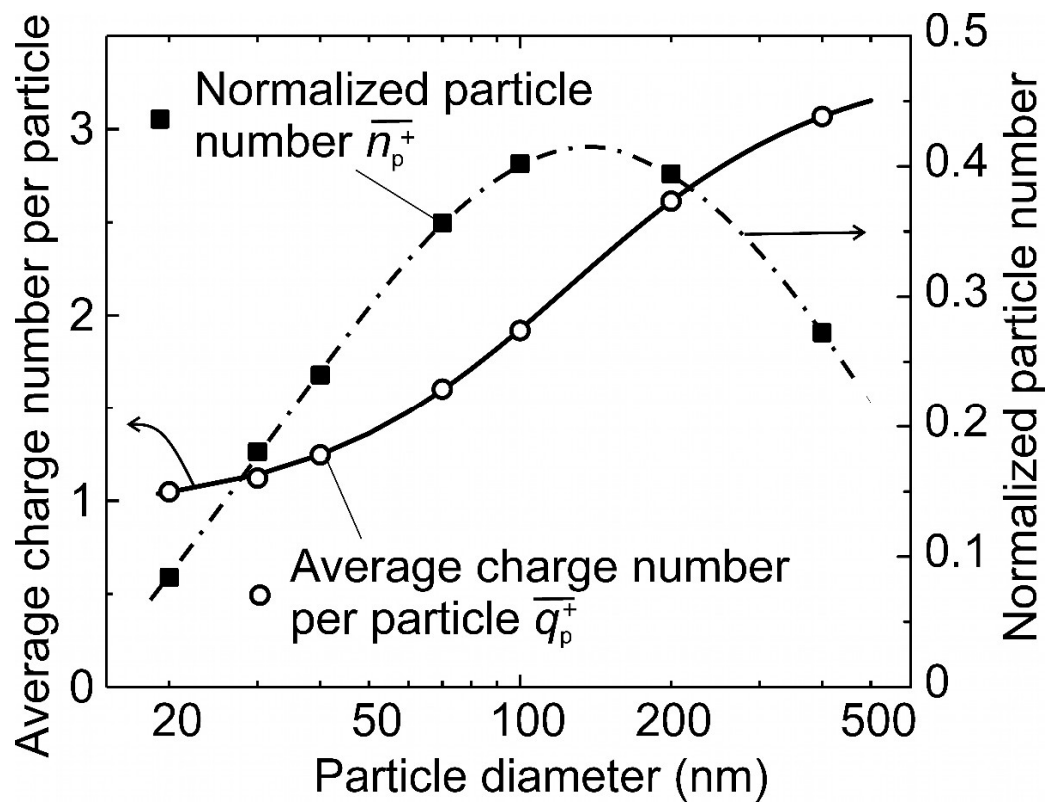

Figure A1. Average charge number per (positive-charged) particle and normalized (positive-charged) particle number of a nebulized $\mathrm{NaCl}$ aerosol.

Table A3. Fitted values using Equation (A3) for the average normalized fraction (open squares, broken line) and for the average charge number (open circles, full line), respectively, of the positivecharged particles shown in Figure A1.

\begin{tabular}{cccccc}
\hline $\boldsymbol{y}_{1}$ & $\boldsymbol{a}_{\mathbf{1}}\left(\mathbf{n m}^{-\mathbf{2}}\right)$ & $\boldsymbol{a}_{\mathbf{2}}\left(\mathbf{n m}^{-\mathbf{1}}\right)$ & $\boldsymbol{a}_{\mathbf{3}}$ & $\boldsymbol{b}_{\mathbf{1}}\left(\mathbf{n m}^{-\mathbf{1}}\right)$ & $\boldsymbol{b}_{\mathbf{1}}$ \\
\hline$\overline{q_{\mathrm{p}}^{+}}$ & -0.281 & 355.2 & -4546 & 398.4 & 20,350 \\
$\overline{n_{\mathrm{p}}^{+}}$ & 3.402 & 92.28 & 13690 & 47.97 & 14,790 \\
\hline
\end{tabular}

\section{Appendix B. Electrostatic Particle Separation/Sampling Using a MEMS-DMPS}

Here we calculate the expected frequency-shift rate of a MEMS-DMPS depending on the applied sampling voltage. We follow the common practice and investigate air-fluidic components for separation of particles in flow channels by computational fluid dynamics 
(CFD) modelling, e.g., using COMSOL Multiphysics [18,19]. Its electrostatic and laminar flow modules are appropriate for electrical-field and air-flow modelling and the "particle tracing for fluid flow module" for computing particle motion under electrical and air-flow fields, where electrical, drag, gravity, and Brownian forces are embedded [32].

We assume smooth and spherical particles carried by a fluid (air) showing no interparticle interactions (collisions) and having a uniform distribution across the inlet of the micro channel $(\mu \mathrm{FC})$. Wall deposition is considered, which may be more probable for small particles due to strong Brownian motion and low particle velocity corresponding to long particle residence in the $\mu \mathrm{FC}$ and can amount up to $\approx 25 \%$ of the total number of nanoparticles $(10 \mathrm{~nm})$ at the outlet a $\mu \mathrm{FC}\left(L_{C}=12 \mu \mathrm{m}, H_{C}=0.6 \mu \mathrm{m}, L_{C} / H_{C}=20\right)$ [36]. However, in our case the $\mu \mathrm{FC}$ has a much lower length to width ratio of $L_{C} / H_{C}=3.73$, and a correspondingly much lower wall deposition efficiency of $\approx 5 \%$ may be expected.

We then calculate the frequency-shift rate vs. sampling voltage $\Delta f / \Delta t=\mathrm{f}\left(V_{\mathrm{es}}\right)$ with a geometrical model of our single-chip MEMS-DMPS comprising the $\mu \mathrm{FC}$ and the cantilever, which was previously described in detail [27]. We use a number of $1000 \times \overline{n_{\mathrm{p}}^{+}}\left(d_{\mathrm{p}}\right)$ particles with average charge numbers $\overline{q_{\mathrm{p}}^{+}}\left(d_{\mathrm{p}}\right)$ and set $d_{\mathrm{p}}$ corresponding to the average values of $j=1, \ldots, 24$ size bins of the FMPS from $19.1 \mathrm{~nm}$ to $523.3 \mathrm{~nm}$ in Table A4. Here, the bins from $6.04 \mathrm{~nm}$ to $16.3 \mathrm{~nm}$ of the FMPS were not considered, since the expected mass concentrations were below the LOD of the MEMS-DMPS of $0.73 \mu \mathrm{g} / \mathrm{m}^{3}$ [27].

Using FEM, the number of particles $\overline{\Delta n_{\mathrm{p}, \mathrm{j}}^{+}}$of the $j$-th size bin with average particle diameter $d_{\mathrm{p}, \mathrm{j}}(j=1, \ldots, 24)$ is determined which are sampled from the initial ensemble of $1000 \times \overline{n_{\mathrm{p}, \mathrm{j}}^{+}}$at $V_{\mathrm{es}, \mathrm{i}}(i=1, \ldots, 6)$, whereby $\overline{n_{\mathrm{p}, \mathrm{j}}^{+}}$is the normalized count of positivecharged particles with an average total charge number $\overline{q_{\mathrm{p}, \mathrm{j}}^{+}}$(see Appendix A). For particle separation/sampling we select voltages of $V_{\mathrm{es}, \mathrm{i}}=-5 \mathrm{~V},-10 \mathrm{~V},-20 \mathrm{~V},-40 \mathrm{~V},-80 \mathrm{~V},-160 \mathrm{~V}$ $(i=1, \ldots, 6)$.

Table A4. Numbering of size bins of FEM/FMPS and MEMS-DMPS ( $j, l$ : Number of particle size bin, $d_{\mathrm{p}, \mathrm{I}, \mathrm{l}}$ : average particle diameter in bin no. $j, l$ ).

\begin{tabular}{cccc}
\hline \multicolumn{1}{c}{ FEM/FMPS } & \multicolumn{2}{c}{ MEMS-DMPS } \\
\hline$j$ & $d_{\mathrm{p}, \mathrm{j}}(\mathrm{nm})$ & $\boldsymbol{l}$ & $\boldsymbol{d}_{\mathrm{p}, \mathbf{l}}(\mathrm{nm})$ \\
\hline 1 & 19.1 & & \\
2 & 22.1 & 1 & \\
3 & 25.5 & & \\
4 & 29.4 & & \\
5 & 34.0 & 2 & \\
6 & 39.2 & & \\
7 & 45.3 & & \\
8 & 52.3 & 3 & \\
9 & 60.4 & & \\
10 & 69.8 & & \\
11 & 80.6 & 4 & \\
12 & 93.1 & & \\
13 & 107.5 & & \\
14 & 124.1 & & \\
15 & 143.3 & 5 & \\
16 & 165.5 & & \\
17 & 191.1 & & \\
18 & 220.7 & & \\
19 & 254.8 & & \\
20 & 294,3 & & \\
21 & 339.8 & & \\
22 & 392.4 & & \\
23 & 453.2 & & \\
24 & 523.3 & &
\end{tabular}


The resulting sampling efficiencies $\xi_{\mathrm{ij}}\left(V_{\mathrm{es}, \mathrm{i}}, d_{\mathrm{p}, \mathrm{j}}\right)$ at each of the 6 voltage values $\left(V_{\mathrm{es}, \mathrm{i}}\right)$ for each of the 24 size bins $\left(d_{\mathrm{p}, \mathrm{j}}\right)$ can be written as a $6 \times 24$ matrix:

$$
\left(\begin{array}{ccc}
\xi_{11} & \cdots & \xi_{124} \\
\vdots & \ddots & \vdots \\
\xi_{61} & \cdots & \xi_{624}
\end{array}\right)
$$

Using this efficiency matrix we can now transform the vector of particle number concentration $\left(c_{n, j}\right)(j=1, \ldots, 24)$ given by the measured size distribution (see Figure 4 ) into a vector of the number of positive-charged particles $\left(\Delta n_{\mathrm{p}, \mathrm{i}}^{+}\right)(i=1, \ldots, 6)$ sampled on the cantilever:

$$
\left(\begin{array}{c}
\Delta n_{\mathrm{p}, 1}^{+} \\
\vdots \\
\Delta n_{\mathrm{p}, 6}^{+}
\end{array}\right)=10^{3}\left(\begin{array}{ccc}
\xi_{11} & \cdots & \xi_{124} \\
\vdots & \ddots & \vdots \\
\xi_{61} & \cdots & \xi_{624}
\end{array}\right)\left(\begin{array}{c}
c_{\mathrm{n}, 1} \\
\vdots \\
c_{\mathrm{n}, 24}
\end{array}\right)
$$

Assuming spherical shape of the model particles and uniform density $\left(\rho_{\text {carbon }}=2.26 \mathrm{~g} / \mathrm{cm}^{3}\right)$ the sampled particle mass vector $\left(\Delta m_{\mathrm{i}}\right)$ can be calculated from $\left(\Delta n_{\mathrm{p}, \mathrm{i}}^{+}\right)(i=1, \ldots, 6)$ :

$$
\left(\begin{array}{c}
\Delta m_{1} \\
\vdots \\
\Delta m_{6}
\end{array}\right)=\frac{\pi}{6} d_{\mathrm{j}}^{3}\left(\begin{array}{c}
\Delta n_{\mathrm{p}, 1}^{+} \\
\vdots \\
\Delta n_{\mathrm{p}, 6}^{+}
\end{array}\right)
$$

and then the related vector of frequency shift rate $\left(\left[\frac{\Delta f}{\Delta t}\right]_{\mathrm{i}}\right)(i=1, \ldots, 6)$ is:

$$
\left(\begin{array}{c}
{\left[\frac{\Delta f}{\Delta t}\right]_{1}} \\
\vdots \\
{\left[\frac{\Delta f}{\Delta t}\right]_{6}}
\end{array}\right)=\frac{f_{0}}{2 m_{0} \Delta t}\left(\begin{array}{c}
\Delta m_{1} \\
\vdots \\
\Delta m_{6}
\end{array}\right)
$$

which are calculated using the values for $f_{0}, m_{0}$ and $\Delta t$ given in Table 3. In Table A5, the components of the resulting frequency-shift-rate vector are given in dependence of the sampling voltage.

Table A5. Numbering and values of sampling voltage for determination of sampling efficiency of the MEMS-DMPS using FEM and for experimental particle sizing using the inversion method.

\begin{tabular}{ccc}
\hline $\boldsymbol{i}$ & $\boldsymbol{V}_{\mathbf{e s}, \mathbf{i}}(\mathbf{V})$ & {$\left[\frac{\Delta f}{\Delta t}\right]_{\mathbf{i}}\left(\frac{\mathrm{Hz}}{\min }\right)$} \\
\hline 1 & -5 & 0.92 \\
2 & -10 & 1.48 \\
3 & -20 & 2.64 \\
4 & -40 & 5.12 \\
5 & -80 & 9.10 \\
6 & -160 & 11.90 \\
\hline
\end{tabular}

These values are plotted in Figure A2 and then fitted using an analytical formula:

$$
\frac{\Delta f}{\Delta t}\left(V_{\mathrm{es}}\right)=a+b \exp \left(c V_{\mathrm{es}}\right)
$$

with coefficients of $a=14.1 \mathrm{~Hz} / \mathrm{min}, b=-14.2 \mathrm{~Hz} / \mathrm{min}$, and $c=-0.012 \mathrm{~V}^{-1}$. 


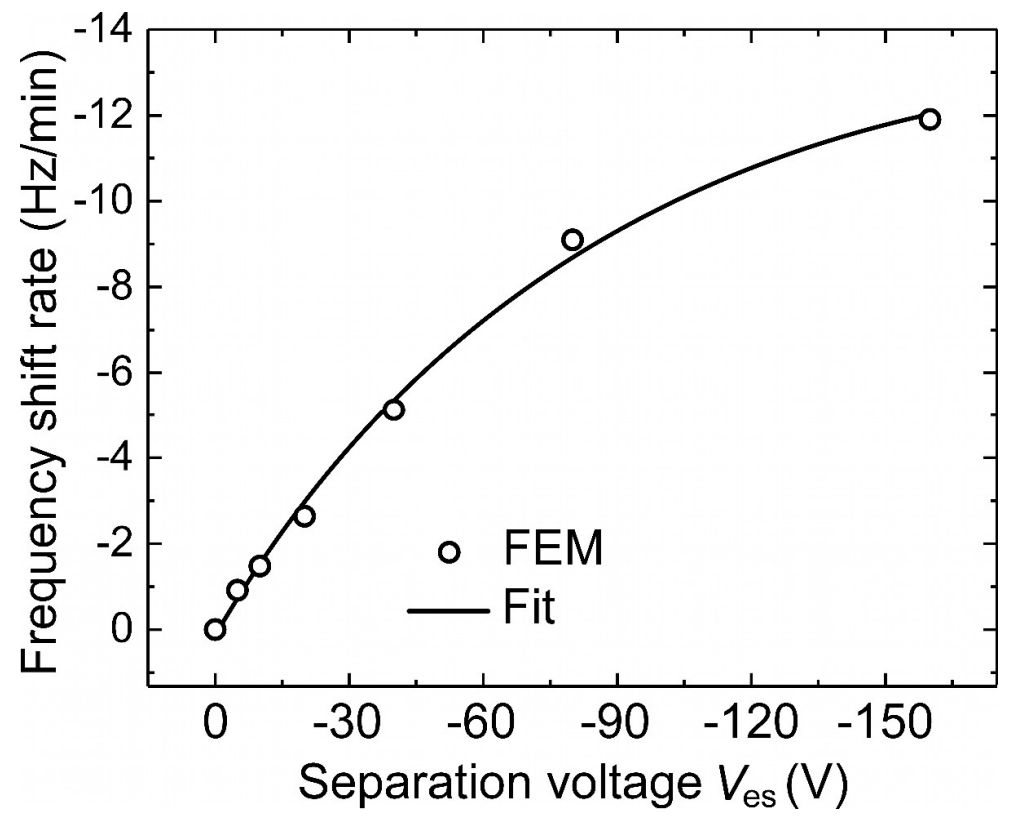

Figure A2. Frequency shift rate determined by FEM for different sampling voltages and fitted curve using Equation (A8).

\section{References}

1. Lelieveld, J.; Klingmüller, K.; Pozzer, A.; Pöschl, U.; Fnais, M.; Daiber, A.; Münzel, T. Cardiovascular disease burden from ambient air pollution in Europe reassessed using novel hazard ratio functions. Eur. Heart J. 2019, 40, 1590-1596. [CrossRef]

2. Pozzer, A.; Dominici, F.; Haines, A.; Witt, C.; Münzel, T.; Lelieveld, J. Regional and global contributions of air pollution to risk of death from COVID-19. Cardiovasc. Res. 2020, 116, 2247-2253. [CrossRef]

3. Moreno-Ríos, A.L.; Tejeda-Benítez, L.P.; Bustillo-Lecompte, C.F. Sources, characteristics, toxicity, and control of ultrafine particles: An overview. Geosci. Front. 2021. Available online: https://www.sciencedirect.com/science/article/pii/S1674987121000116 (accessed on 23 April 2021).

4. Diabaté, S.; Armand, L.; Murugadoss, S.; Dilger, M.; Fritsch-Decker, S.; Schlager, C.; Béal, D.; Arnal, M.-E.; Biola-Clier, M.; Ambrose, S.; et al. Air-Liquid Interface Exposure of Lung Epithelial Cells to Low Doses of Nanoparticles to Assess Pulmonary Adverse Effects. Nanomaterials 2021, 11, 65. [CrossRef]

5. Kaliszewski, M.; Włodarski, M.; Młynczak, J.; Kopczynski, K. Comparison of Low-Cost Particulate Matter Sensors for Indoor Air Monitoring during COVID-19 Lockdown. Sensors 2020, 20, 7290. [CrossRef] [PubMed]

6. Alfano, B.; Barretta, L.; Del Giudice, A.; De Vito, S.; Di Francia, G.; Esposito, E.; Formisano, F.; Massera, E.; Miglietta, M.L.; Polichetti, T. A Review of Low-Cost Particulate Matter Sensors from the Developers' Perspectives. Sensors 2020, $20,6819$. [CrossRef] [PubMed]

7. Molaie, S.; Lino, P. Review of the Newly Developed, Mobile Optical Sensors for Real-Time Measurement of the Atmospheric Particulate Matter Concentration. Micromachines 2021, 12, 416. [CrossRef]

8. Soysal, U.; Géhin, E.; Algré, E.; Berthelot, B.; Da, G.; Robine, E. Aerosol mass concentration measurements: Recent advancements of real-time nano/micro systems. J. Aerosol Sci. 2017, 114, 42-54. [CrossRef]

9. Wasisto, H.S.; Merzsch, S.; Stranz, A.; Waag, A.; Uhde, E.; Salthammer, T.; Peiner, E. Silicon resonant nanopillar sensors for airborne titanium dioxide engineered nanoparticle mass detection. Sens. Actuators B 2013, 189, 146-156. [CrossRef]

10. Chellasivalingam, M.; Imran, H.; Pandit, M.; Boies, A.M.; Seshia, A.A. Weakly Coupled Piezoelectric MEMS Resonators for Aerosol Sensing. Sensors 2020, 20, 3162. [CrossRef]

11. Poenar, D.P. Microfluidic and Micromachined/MEMS Devices for Separation, Discrimination and Detection of Airborne Particles for Pollution Monitoring. Micromachines 2019, 10, 483. [CrossRef] [PubMed]

12. Mouro, J.; Pinto, R.; Paoletti, P.; Tiribilli, B. Microcantilever: Dynamical Response for Mass Sensing and Fluid Characterization. Sensors 2021, 21, 115. [CrossRef]

13. Wasisto, H.S.; Merzsch, S.; Uhde, E.; Waag, A.; Peiner, E. Handheld personal airborne nanoparticle detector based on microelectromechanical silicon resonant cantilever. Microelectron. Eng. 2015, 145, 96-103. [CrossRef]

14. Setiono, A.; Bertke, M.; Nyang'au, W.O.; Xu, J.; Fahrbach, M.; Kirsch, I.; Uhde, E.; Deutschinger, A.; Fantner, E.J.; Schwalb, C.H.; et al. In-plane and out-of-plane MEMS piezoresistive cantilever sensors for nanoparticle mass detection. Sensors 2020, 20, 618. [CrossRef] [PubMed] 
15. Bao, Y.; Cai, S.; Yu, H.; Xu, T.; Xu, P.; Li, X. A resonant cantilever based particle sensor with particle-size selection function. J. Micromech. Microeng. 2018, 28, 085019. [CrossRef]

16. Liu, T.-Y.; Sung, C.-A.; Weng, C.-H.; Chu, C.-C.; Zope, A.-A.; Pillai, G.; Li, S.-S. Gated CMOS-MEMS thermal-piezoresistive oscillator-based $\mathrm{PM}_{2.5}$ sensor with enhanced particle collection efficiency. In Proceedings of the MEMS 2018, Belfast, Northern Ireland, UK, 21-25 January 2018; pp. 75-78.

17. Qin, X.; Xian, X.; Deng, Y.; Wang, D.; Tsow, F.; Forzani, E.; Tao, N. Micro Quartz Tuning Fork based PM 2.5 Sensor for Personal Exposure Monitoring. IEEE Sens. J. 2019, 19, 2482-2489. [CrossRef]

18. Wang, Y.; Wang, Y.; Liu, W.; Chen, D.; Wu, C.; Xie, J. An aerosol sensor for PM1concentration detection based on 3D printed virtual impactor and SAW sensor. Sens. Actuators A 2019, 288, 67-74. [CrossRef]

19. Fahimi, D.; Mahdavipour, O.; Sabino, J.; White, R.M.; Paprotny, I. Vertically-stacked MEMS PM 2.5 sensor for wearable applications. Sens. Actuators A 2019, 299, 111569. [CrossRef]

20. Weng, C.-H.; Pillai, G.; Li, S.-S. A PM 2.5 Sensor Module Based on a TPoS MEMS Oscillator and an Aerosol Impactor. IEEE Sens. J. 2020, 20, 14722-14731. [CrossRef]

21. Maldonado-Garcia, M.; Wilson, J.C.; Pourkamali, S. Horizontal Chip-Scale Cascade Impactor with Integrated Resonant Mass Balances. In Proceedings of the 2016 IEEE 29th International Conference on Micro Electro Mechanical Systems (MEMS), Shanghai, China, 24-28 January 2016; pp. 1070-1073.

22. Lee, S.-M.; Kim, H.-L.; Kwon, H.-B.; Kim, K.; Yoo, S.-J.; Hong, U.-S.; Hwang, J.; Kim, Y.-J. MEMS Based Particle Size Analyzer Using Electrostatic Measuring Techniques. In Proceedings of the 2019 20th International Conference on Solid-State Sensors, Actuators and Microsystems \& Eurosensors XXXIII (TRANSDUCERS \& EUROSENSORS XXXIII), Berlin, Germany, 23-27 June 2019; pp. 1289-1292.

23. Liu, Q.; Liu, D.; Chen, X.; Zhang, Q.; Jiang, J.; Chen, D.-R. Cost-effective, Miniature Electrical Ultrafine Particle Sizer (mini-eUPS) for Ultrafine Particle (UFP) Monitoring Network. Aerosol Air Qual. Res. 2020, 20, 231-241. [CrossRef]

24. Kwon, H.-B.; Song, W.-Y.; Lee, T.-H.; Lee, S.-S.; Kim, Y.-J. Monitoring the Effective Density of Airborne Nanoparticles in Real Time Using a Microfluidic Nanoparticle Analysis Chip. ACS Sens. 2021, 6, 137-147. [CrossRef] [PubMed]

25. Bertke, M.; Wu, W.; Wasisto, H.S.; Uhde, E.; Peiner, E. Size-Selective Electrostatic Sampling and Removal of Nanoparticles on Silicon Cantilever Sensors for Air-Quality Monitoring. In Proceedings of the 19th International Conference on Solid-State Sensors, Actuators and Microsystems (Transducers 2017), Kaohsiung, Taiwan, 18-22 June 2017; pp. 1493-1496.

26. Bertke, M.; Xu, J.; Fahrbach, M.; Setiono, A.; Wasisto, H.S.; Peiner, E. Strategy toward miniaturized, self-out-readable resonant cantilever and integrated electrostatic microchannel separator for highly sensitive airborne nanoparticle detection. Sensors 2019, 19, 901. [CrossRef]

27. Bertke, M.; Xu, J.; Setiono, A.; Kirsch, I.; Uhde, E.; Peiner, E. Fabrication of a micro-cantilever-based aerosol detector with integrated electrostatic on-chip ultrafine particle separation and collection. J. Micromech. Microeng. 2020, 30, 014001. [CrossRef]

28. Zhang, Y. Indoor Air Quality Engineering; CRC Press: Boca Raton, FL, USA, 2004; pp. 379-385.

29. Buiarelli, F.; Di Filippo, P.; Massimi, L.; Pomata, D.; Riccardi, C.; Simonetti, G.; Sonego, E. Ultrafine, fine and coarse airborne particle mass concentration in workplaces. Atmos. Pollut. Res. 2019, 10, 1685-1690. [CrossRef]

30. Maierhofer, P.; Röhrer, G.; Bainschab, M.; Bergmann, A. On the Inherent Variability of Particulate Matter Concentrations on Small Scales and the Consequences for Miniaturized Particle Sensors. Aerosol Air Qual. Res. 2020, 20, 271-280. [CrossRef]

31. Yang, J.; Wang, H.; Zhou, J.; Chen, D.-R.; Kong, D.; Yu, F.; Gui, H.; Liu, J.; Chen, M. A Build-In Data Inversion Method to Retrieve Aerosol Size Distributions for a Portable Ultrafine Particle Sizer (PUPS). IEEE Access 2021, 9, 2879-2889. [CrossRef]

32. Ngo, N.D.; Lee, J.; Kim, M.-W.; Jang, J. Measurement of PM2:5 Mass Concentration Using an Electrostatic Particle ConcentratorBased Quartz Crystal Microbalance. IEEE Access 2019, 7, 170640-170647. [CrossRef]

33. Simones, M.P.; Loyalka, S.K.; Duffy, C.; MacLoughlin, R.; Tatham, A.; Power, P. Measurement of the size and charge distribution of sodium chloride particles generated by an Aeroneb Pro ${ }^{\circledR}$ pharmaceutical nebulizer. Eur. J. Nanomed. 2014, 6, 29-36. [CrossRef]

34. Wasisto, H.S.; Merzsch, S.; Waag, A.; Kirsch, I.; Uhde, E.; Salthammer, T.; Peiner, E. Portable cantilever-based airborne nanoparticle detector. Sens. Actuators B 2013, 187, 118-127. [CrossRef]

35. Maldonado-Garcia, M.; Kumar, V.; Wilson, J.C.; Pourkamali, S. Chip-Scale Implementation and Cascade Assembly of Particulate Matter Collectors with Embedded Resonant Mass Balances. IEEE Sens. J. 2017, 17, 1617-1625. [CrossRef]

36. Bao, F.; Hao, H.; Yin, Z.; Tu, C. Numerical Study of Nanoparticle Deposition in a Gaseous Microchannel under the Influence of Various Forces. Micromachines 2021, 12, 47. [CrossRef] [PubMed] 